Faculty of Science

Faculty Publications

Polar lows in the Labrador Sea

G.W.K. Moore, M.C. Reader, J. York \& S. Sathiyamoorthy

1996

(C) 1996 G.W.K. Moore, M.C. Reader, J. York \& S. Sathiyamoorthy. This article is an open access article distributed under the terms and conditions of the Creative Commons Attribution (CC BY) license. http://creativecommons.org/licenses/by/4.0/

This article was originally published at:

https://doi.org/10.3402/tellusa.v48i1.11630

Citation for this paper:

Moore, G. W. K., Reader, M. C., York, J. \& Sathiyamoorthy, S. (1996). Polar lows in the Labrador Sea. Tellus A: Dynamic Meteorology and Oceanography, 48(1), 17-40. https://doi.org/10.3402/tellusa.v48i1.11630 


\title{
Polar lows in the Labrador Sea
}

\author{
G.W.K. Moore, M.C. Reader, J. York \& S. Sathiyamoorthy
}

To cite this article: G.W.K. Moore, M.C. Reader, J. York \& S. Sathiyamoorthy (1996) Polar lows in the Labrador Sea, Tellus A: Dynamic Meteorology and Oceanography, 48:1, 17-40, DOI: 10.3402/ tellusa.v48i1.11630

To link to this article: https://doi.org/10.3402/tellusa.v48i1.11630
а
(C) 1996 Munksgaard

曲 Published online: 15 Dec 2016.

Submit your article to this journal $\pi$

凹 Article views: 22

Q View related articles $\sqsubset$

Citing articles: 13 View citing articles 


\title{
Polar lows in the Labrador Sea
}

\author{
A case study
}

\author{
By G. W. K. MOORE*, M. C. READER ${ }^{1}$, J. YORK ${ }^{2}$ and S. SATHIYAMOORTHY ${ }^{3}$, Department of \\ Physics, University of Toronto, Toronto, Ontario, M5S 1A7, Canada
}

(Manuscript received 29 August 1994; in final form 27 April 1995)

\begin{abstract}
In this paper, we will describe our analysis of a polar low event that occurred in the Labrador Sea during the winter of 1992. As there are unfortunately no in-situ observations of this event, we will rely on satellite data as well as the high-resolution objective analaysis from the ECMWF to document the environment in which the low developed and the structure of the low itself. We will show that the polar low developed during a cold air outbreak that was precipitated by the passage of an intense synoptic-scale low. The polar low appears to have developed along a linear cloud feature as the result of an interaction between a low-level diabatically induced potential vorticity anomaly and an upper-level potential vorticity anomaly that propagated into the area from the Canadian Arctic. We will also show that with the TOMS and TOVS retrievals for total column ozone, we are able to identify a signature of the upper-level potential vorticity anomaly. In its mature state, we will show that there were very strong winds, and as a result large fluxes of sensible and latent heat, associated with the polar low. In summary, the 1992 Labrador Sea polar low provides one with an excellent opportunity to study air-sea interactions and the coupling between the troposphere and stratosphere. The realization that the strong heating of the atmosphere and the concomitant cooling of the ocean associated with these storms may be sufficient to initiate downwelling events in the ocean may represent a hitherto undocumented link between the fast and slow climate systems that deserves further attention.
\end{abstract}

\section{Introduction}

During the past 20 years, it has become apparent that intense and rapidly developing mesoscale vortices are often observed north of the primary Polar Front. These vortices, known as polar lows, occur primarily over the high latitude oceans and are of interest for a variety of reasons.

${ }^{1}$ Present Affliation: Canadian Climate Centre, Environment Canada, University of Victoria, Victoria, British Columbia V8W 2Y2, Canada.

${ }^{2}$ Present Affliation: Department of Geology and Geophysics, University of Minnesota, Minneapolis, MN 55455, USA.

${ }^{3}$ Present Affliation: Center for Meteorology and Physical Oceanography, Massachusetts Institute of Technology, Cambridge, MA 02139, USA.

* Corresponding author.
Their initial growth and organization appear to be baroclinic in origin, yet the time and length scales associated with them are significantly shorter than is predicted by conventional instability theory (Rasmussen, 1985; Reed and Duncan, 1987; Moore and Peltier, 1989). Satellite imaginary of the cloud fields associated with these vortices shows a high degree of structure that suggests that interactions between cloud scale, mesoscale and synoptic scale processes are occurring during their evolution (Douglas and Shapiro, 1989; Rasmussen et al., 1992). Their small size and rapid development make them particularly difficult to forecast (Rasmussen and Lystad, 1987). One also often observes strong surface fluxes of heat and moisture to be associated with these vortices (Shapiro et al., 1987). Indeed, their rapid development can for the most part be attributed to the convective activity driven by these fluxes (Rasmussen, 1989). It is 
unclear what effect the same fluxes have on the ocean. It appears that the magnitude of the cooling experienced by the ocean is sufficiently large that it may result in convective overturning of the mixed layer. In this sense, the polar lows could represent the source of the sudden atmospheric forcing, i.e., cooling, required by the theory of deep water formation proposed by Killworth (1983). In this regard it is interesting to note that the Labrador Sea is one of the few areas of the world in which abyssal water formation occurs (Gascard and Clarke, 1983; Carmack, 1990).

Polar lows were first identified in the Norwegian Sea (Harley, 1960; Pedgley, 1968; Harrold and Browning, 1969) and research has naturally tended to focus on those that develop there. In recent years it has become apparent that they also commonly occur in other areas of the world including, among others, the Gulf of Alaska, the Sea of Japan, the Beaufort Sea and Antarctica. Very recently, it has been realized that the Labrador Sea is also a region in which the frequency of mesoscale cyclogenesis and the concomitant development of polar lows is also high (Parker and Hudson, 1991; Rasussen and Purdom, 1992; Rasmussen et al., 1995).

In this paper, we will describe our analysis of a polar low event that occurred in the Labrador Sea during the winter of 1992. As there are unfortunately no in-situ observations of this event, we will rely on satellite data as well as the high resolution objective analysis from the ECMWF to document the environment in which the low developed and the structure of the low itself.

\section{Data}

\subsection{Satellite data}

In this sort of study, it has become conventional to employ imagery and/or sounding data from both the NOAA and DMSP families of polar orbiting satellites to document the structure and evolution of systems under investigation (Turner et al., 1992; Claud et al., 1992). In addition we will also make use of what is, at least to the polar low community, a new source of data; satellite based retrievals for total column ozone. As will be shown the ozone retrievals shed considerable light on the processes responsible for the development of polar lows.
The NOAA satellite data used in this paper was collected by the Atmospheric Physics Group from the University of Toronto during the second phase of the Canadian Atlantic Storms Project (CASP II). The full digital High Resolution Picture Transmission (HRPT) consisting of data from both the Advanced Very High Resolution Radiometer (AVHRR) and TIROS-N Operational Vertical Sounder (TOVS) instruments was received with a portable ground station that was deployed in Torbay Newfoundland during the months of February-March 1992. The location of the receiver at the extreme eastern edge of the North American continent provided for an excellent coverage of the North Atlantic. Supplementary data for passes that were missed in the field were obtained from the archive of the Atmospheric Environment Service of Canada.

The AVHRR is a 5 channel, 2 visible and 3 infrared, imaging radiometer that has a resolution at nadir of approximately $1.1 \mathrm{~km}$. Calibration, registration and display of the AVHRR data was done with the Terascan software system developed by Seaspace Inc. For clarity of exposition, brightness temperatures inferred from calibrated AVHRR data will be referred to as temperatures in this paper. They will be displayed in reverse grey scale with colder objects appearing brighter and warmer objects appearing darker. The TOVS instrument consists of three sounding units; the High Resolution Infrared Sounder (HIRS); the Microwave Sounder Unit (MSU) and the Stratospheric Sounder Unit (SSU). Data from the SSU was not used in this paper. The HIRS is a twenty channel passive radiometer that has a resolution at nadir of approximately $40 \mathrm{~km}$ and is the primary source of sounding information in clear or partly cloudy conditions. The MSU is a 4-channel passive microwave radiometer that has a resolution at nadir of approximately $120 \mathrm{~km}$ and is used to identify cloud contamination problems with the HIRS radiances. It is also the primary source of sounding information in cloudy conditions. The TOVS data was processed with version 3 of the International TOVS Processing Package (Smith et al., 1985) as implemented in the Terascan software system. In addition to the conventional retrievals for temperature, relative humidity and geopotential, we will also consider a total column ozone retrieval that uses several of the TOVS infrared and microwave channels (Smith et al., 
1985). The resolution of the TOVS retrievals is a complex function of cloud cover but can generally be assumed to be on the order of $100 \mathrm{~km}$ (Turner et al., 1992; Claud et al., 1992).

The Special Sensor Microwave/Imager (SSM/I) data from satellites F10 and F11 in the DMSP series was obtained from Remote Sensing Systems Inc. The SSM/I is a 7 channel passive microwave radiometer. Dual polarization measurements are made at $19 \mathrm{GHz}, 35 \mathrm{GHz}$ and $85 \mathrm{GHz}$ while vertical polarization measurements are made at $22 \mathrm{GHz}$. The resolution of the instrument is of course a function of frequency and varies from approximately $70 \mathrm{~km}$ for the $19 \mathrm{GHz}$ channel to approximately $15 \mathrm{~km}$ for the $85 \mathrm{GHz}$ channel. Using algorithms described in Petty (1990), the SSM/I data was used to obtain estimates of surface wind speed, integrated water vapour, integrated cloud liquid water, and an index, S85, of the scattering of the upwelling microwave radiation by large ice particles. The latter makes use of the fact that the highly polarized microwave emissions from the ocean's surface tend to be depolarized as a result of scattering by precipitation and/or ice crystals. The $85 \mathrm{GHz}$ channel is especially sensitive to scattering by ice crystals and as a result the S85 index provides an indication as to whether or not deep convection is present. According to Petty (1990), values of the index in excess of 10 are indicative of convective activity. Any pixels in which precipitation contamination was sufficiently severe so as to render the retrievals questionable were excluded from the analysis. During the period of interest, there are unfortunately some missing passes in the Remote Sensing Systems' DMSP archive. In particular, there are only a few passes over the Labrador Sea for which data is available during the early stages of the low's development.

Total column ozone data from the Total Ozone Mapping Spectrometer (TOMS) on the Nimbus 7 platform will also be used in this study. The TOMS is a scanning spectrometer that uses backscattered ultra-violet radiation to deduce total column ozone. It has a horizontal resolution at nadir of approximately $50 \mathrm{~km}$. In this paper we used a derived product known as "Grid TOMS" (McPeters et al., 1993) that provides global coverage, at local noon, with a horizontal resolution of approximately $1 \mathrm{deg}$.

Both the TOMS and TOVS column ozone retrievals will be used to infer the existence of intrusions into the upper-troposphere of ozone rich stratospheric air that may, following the conceptual model of Hoskins, McIntyre and Robertson (1985; hereafter HMR), play a role in the genesis of the low. Although both have a nominal resolution of approximately $100 \mathrm{~km}$, the TOMS data appears to have been subject to smoothing that filters out fine mesoscale structure. For the purposes of identifying the rôle that upperlevel structures play in the development of the low, the TOVS ozone retrieval has the distinct advantage of being coincident with the AVHRR imagery.

\subsection{Objectively analysed fields}

In order to document the synoptic scale environment in which the low developed, we will rely on the ECMWF/WCRP Level III-A advanced surface and upper-air analysis. Standard surface and upper-level fields are included in the analysis, as well as certain derived or supplementary fields such as surface fluxes of sensible and latent heat. The data assimilation model is run at a triangular truncation of T213 with 31 levels in the vertical. The level IIIa dataset is available at a triangular truncation of T106 with 15 levels in the vertical $(1000,925,850,700,500,400,300,250,200,150$, $100,70,50,30$, and $10 \mathrm{mb}$ ). It has been interpolated from its original Gaussian grid to one with a uniform horizontal resolution of $1.125^{\circ}$. This data is available 4 times daily $(0,6,12$ and 18 GMT). The upper-level fields were also interpolated to isentropic co-ordinates to facilitate an analysis of isentropic surfaces. The ECMWF's focus on medium range forecasting allows them very long data collection times (up to $18 \mathrm{~h}$ ) for incorporation of data into their analysis cycle. This is an advantage for a study such as this one as it allows for the possibility that all the satellite sounding data as well as late data from remote stations will be included in the analysis. The analysed fields were obtained from the Data Support Section at NCAR and were displayed with the GEMPAK software package developed at NMC and NCAR.

\section{Evolution and structure of the polar low}

The polar low under investigation developed during a cold air outbreak that was precipitated by an intense and rapidly deepening synoptic-scale 
cyclone that propagated into the Labrador Sea on 13 February 1992. According to the ECMWF analysis, the synoptic low reached a maximum depth of $960 \mathrm{mb}$ at $12 \mathrm{GMT}$ on the 13th. Over the previous $24 \mathrm{~h}$, it had deepened by approximately $35 \mathrm{mb}$. As the low impinged on Greenland it underwent a rapid decay. However, a secondary development occurred along a weak trough that extended to the southeast. This secondary synoptic low slowly propagated westward towards Greenland and dissipated after landfall on the 15th.
Fig. 1 shows an IR image from the NOAA 11 pass at 17:17 GMT on 13 February 1992. This corresponds to the approximate time of first landfall of the primary synoptic low. The center of this system can be clearly seen near Cape Farewell. At this time its central pressure was approximately $965 \mathrm{mb}$. Over the next $6 \mathrm{~h}$, the central pressure rose by approximately $15 \mathrm{mb}$ and the low dissipated, leaving the aforementioned weak trough along which the secondary disturbance developed. Fig. 2 shows the ECMWF analysed mean sea level

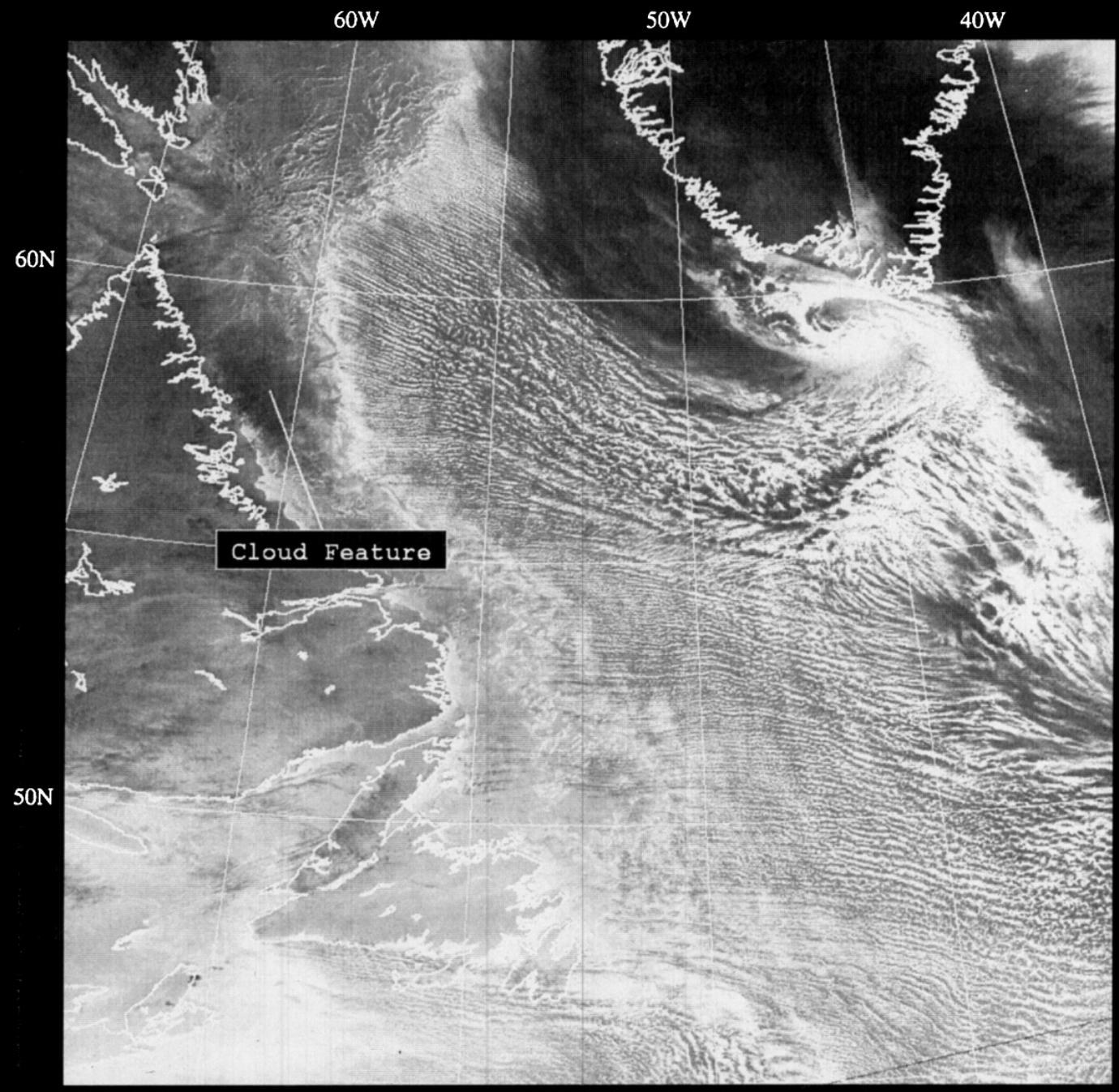

Fig. 1. IR image from the NOAA 11 pass at 17:17 GMT on 13 February 1992, showing the synoptic scale low whose passage through the Labrador Sea preceded the development of the polar low. The amorphous cloud field out of which the linear cloud band developed is indicated. 
pressure and $10 \mathrm{~m}$ winds at four times during period of interest. From Figs. 2a and b, 18 GMT on the 13th and 0 GMT on the 14th, one can clearly see the decay of the primary low into a weak trough to the south and east of Greenland. While in Fig. 2c, 6 GMT on the 14th, the secondary synoptic low that formed along the trough left over from the decay of the primary low can be seen.

Fig. 1 also shows that a cloud feature is present on the landfast ice just offshore of Northern Labrador near $57.5^{\circ} \mathrm{N}, 60^{\circ} \mathrm{W}$. The amorphous nature of this feature is in sharp contrast to the organized banded structure of the streamers over the Labrador Sea itself. No evidence of this feature is visible on earlier images from the 13th. The 10 wind field at 18 GMT on the 13th, Fig. 2a, indicates that there was a region of weak horizontal convergence in the vicinity of where the cloud formed. This region appears to be associated with a weak ridge that formed over the Torngat Mountains of Northern Labrador. Over the next $18 \mathrm{~h}$, the cloud field was advected out over the Labrador (a) 18 GMT, Feb. 131992

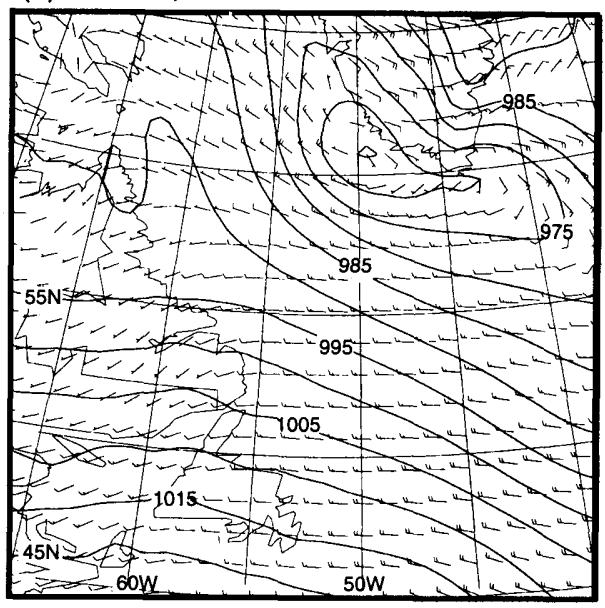

(c) 06 GMT, Feb.14 1992

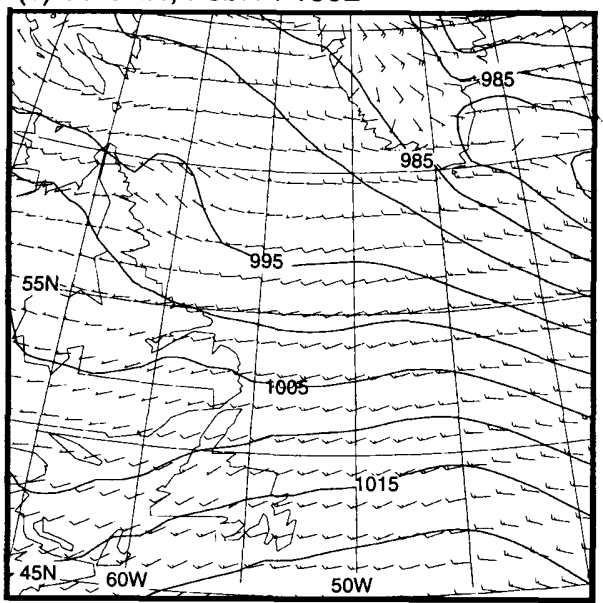

(b) 00 GMT, Feb. 141992

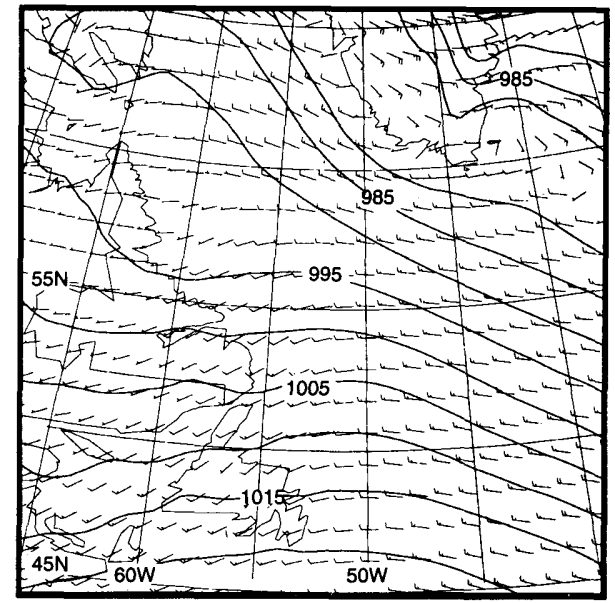

(d) 18 GMT, Feb.15 1992

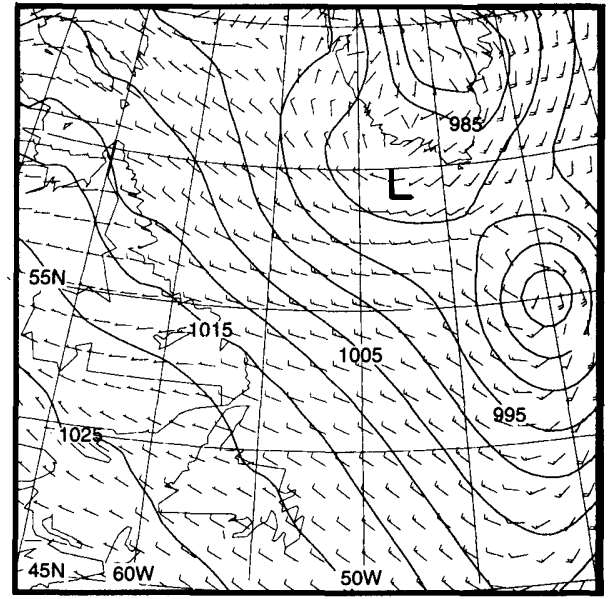

Fig. 2. Sea-level pressure $(\mathrm{mb})$ and $10 \mathrm{~m}$ winds $(\mathrm{m} / \mathrm{s})$ as analysed by the ECMWF for 4 times during the life-cycle of the polar low: (a) 18 GMT on 13 February 1992, (b) 00 GMT on 14 February 1992, (c) 06 GMT on 14 February 1992, and (d) 18 GMT on 15 February 1992. The location of the polar low is indicated by the "L" in panel (d). 
Sea where it underwent further organization culminating in the quasi-linear feature evident in Fig. 3 which shows an IR image from the NOAA 12 pass at 11:42 GMT on the 14th. Overlaid on the image is the SSM/I derived surface wind speed as determined from the F10 pass at 12:25 GMT on the 14th. The organization of the rather amorphous cloud feature present at the earlier time into the highly organized linear feature present at this time is rather striking. It is quite likely that cloud scale feedback processes such as symmetric instability and CISK played a rôle in the high degree of organization of this feature.

From this figure, one can also see that the cloud feature is aligned with the region of strong surface winds, in excess of $14 \mathrm{~m} / \mathrm{s}$, in the Labrador Sea. The ECMWF analysis was unable to resolve this mesoscale jet. Indeed the analysis at 12 GMT on the 14th indicated that the maximum wind speed in the Labrador Sea was only $8 \mathrm{~m} / \mathrm{s}$. An analysis of the brightness temperatures which form the basis of the SSM/I wind speed retrieval showed no

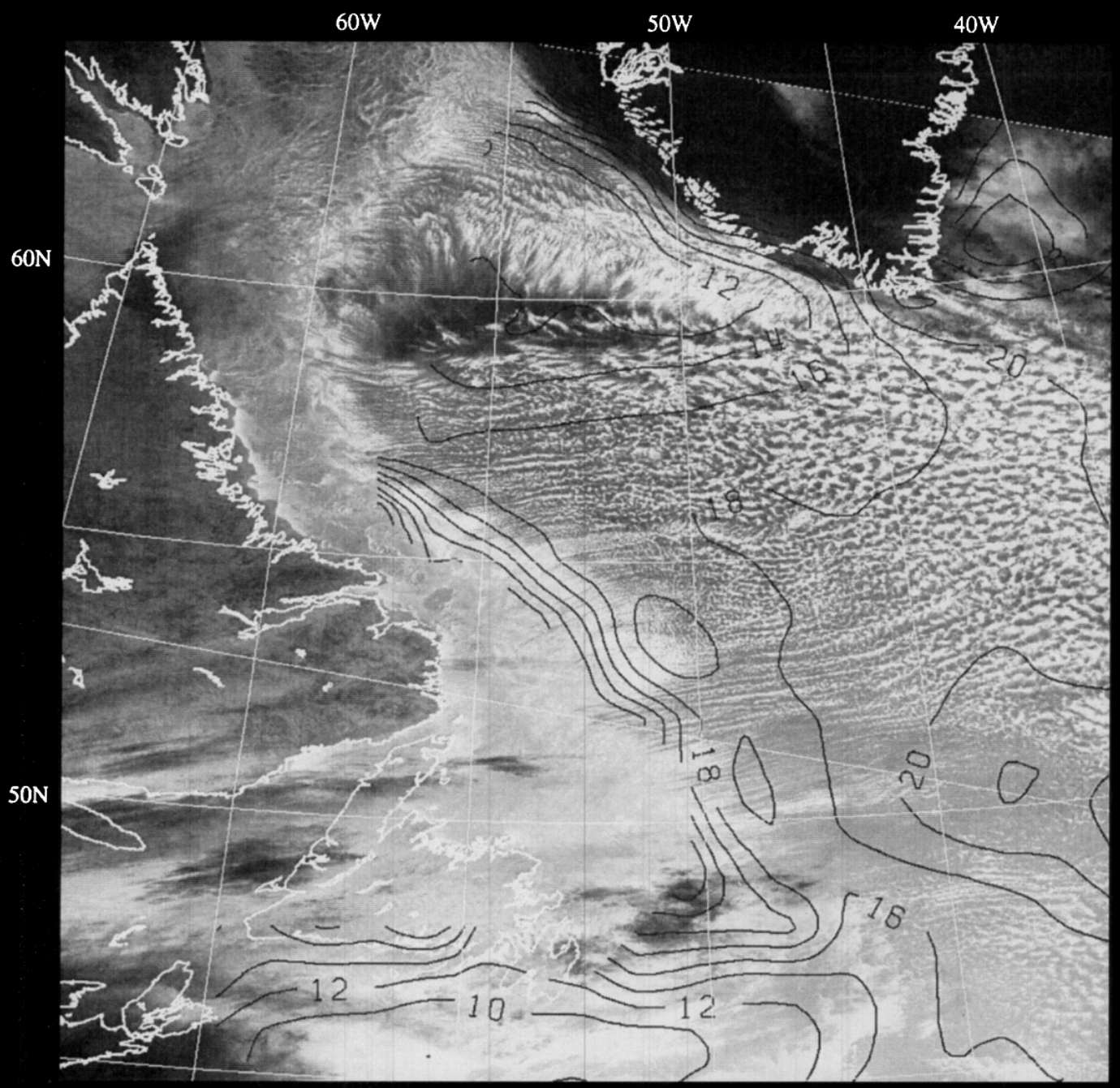

Fig. 3. IR image from the NOAA 12 pass at 11:42 GMT on 14 February 1992 showing the nascent cloud band that developed out of the amorphous feature displayed in Fig. 1. Overlaid on the image is the SSM/I derived wind speed $(\mathrm{m} / \mathrm{s})$ as determined from the F10 pass at 12:25 GMT on 14 February 1992. 
obvious indications of precipitation contamination that could account for this discrepancy. This suggests that it was the ECMWF analysis that was at fault. This is again not surprising, given the lack of conventional data in this area. The SSM/I wind field analysis also shows some barotropic shear across this jet. The maximum shear across the jet was approximately $0.1 \mathrm{f}$. The algorithm used to compute wind speed from the SSM/I data makes use of the $19 \mathrm{GHz}$ data and as a result, the resolution of the analysis is, at best, on the order of
$70 \mathrm{~km}\left(2 / 3^{\circ}\right.$ of latitude). It is entirely possible that the shear was contained in a much narrower latitudinal belt than was resolved by the SSM/I wind speed retrieval.

Fig. 4 shows an IR image from a NOAA 11 pass at 17:01 GMT on 14 February 1992. Overlaid on the image is the TOVS derived $1000-500 \mathrm{mb}$ geopotential thickness field. The cloud top temperatures along the line were approximately uniform at $-40^{\circ} \mathrm{C}$. From this figure, one can also see that a train of at least 4 small scale vortices had

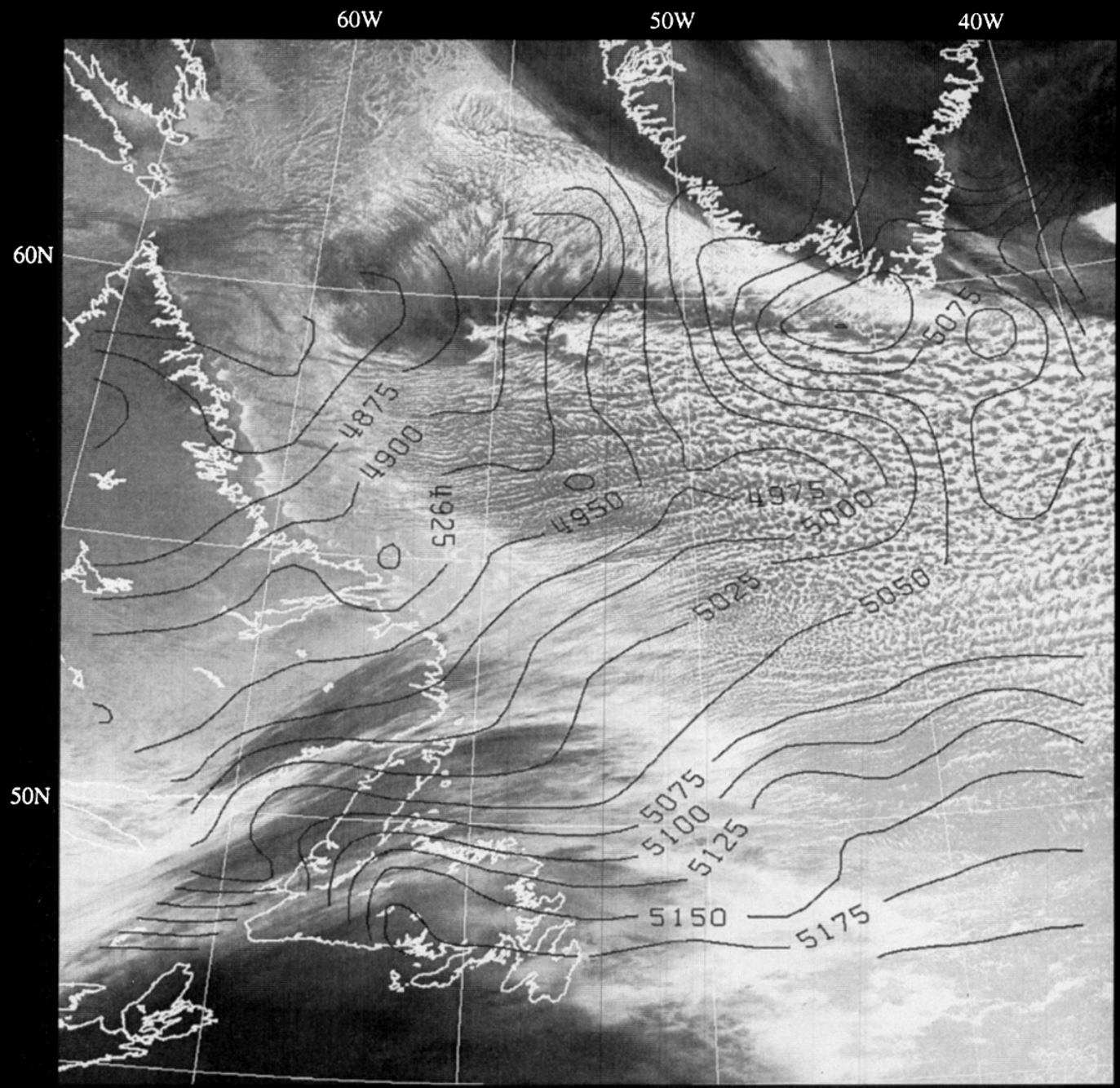

Fig. 4. IR image from the NOAA 11 pass at 17:01 GMT on 14 February 1992 showing the highly organized cloud band that developed out the amorphous feature displayed in Fig. 1. Overlaid on the image is the TOVS derived $1000-500 \mathrm{mb}$ geopotential thickness $(\mathrm{m})$ for the same pass. 
developed along the cloud line near its western edge in the vicinity of $58^{\circ} \mathrm{N}, 55^{\circ} \mathrm{W}$. The spacing of the vortices was on the order of $50 \mathrm{~km}$. The process or processes responsible for their development is not at all obvious. Their short wavelength suggest that they were not a manifestation of the arctic instability mechanism discussed by Rasmussen et al. (1992). The timescale for their development was on the order of $6 \mathrm{~h}$. The presence of the barotropic jet described above suggests that the vortices along the line are possibly the result of the jet being unstable to a mixed barotropic-con- vective instability of the form discussed by Moore (1985). If one takes the SSM/I wind speed analysis at face value, then the shear across the jet was probably not sufficiently strong to destabilize the line in the manner observed. However, if the weak shear was an artifact of the coarse resolution of the SSM/I analysis and the jet was indeed much narrower than depicted in Fig. 3, then the picture changes dramatically and one may indeed have had a jet that could have gone unstable in a manner consistent with the observations.

From the thickness field in Fig. 4, it is evident

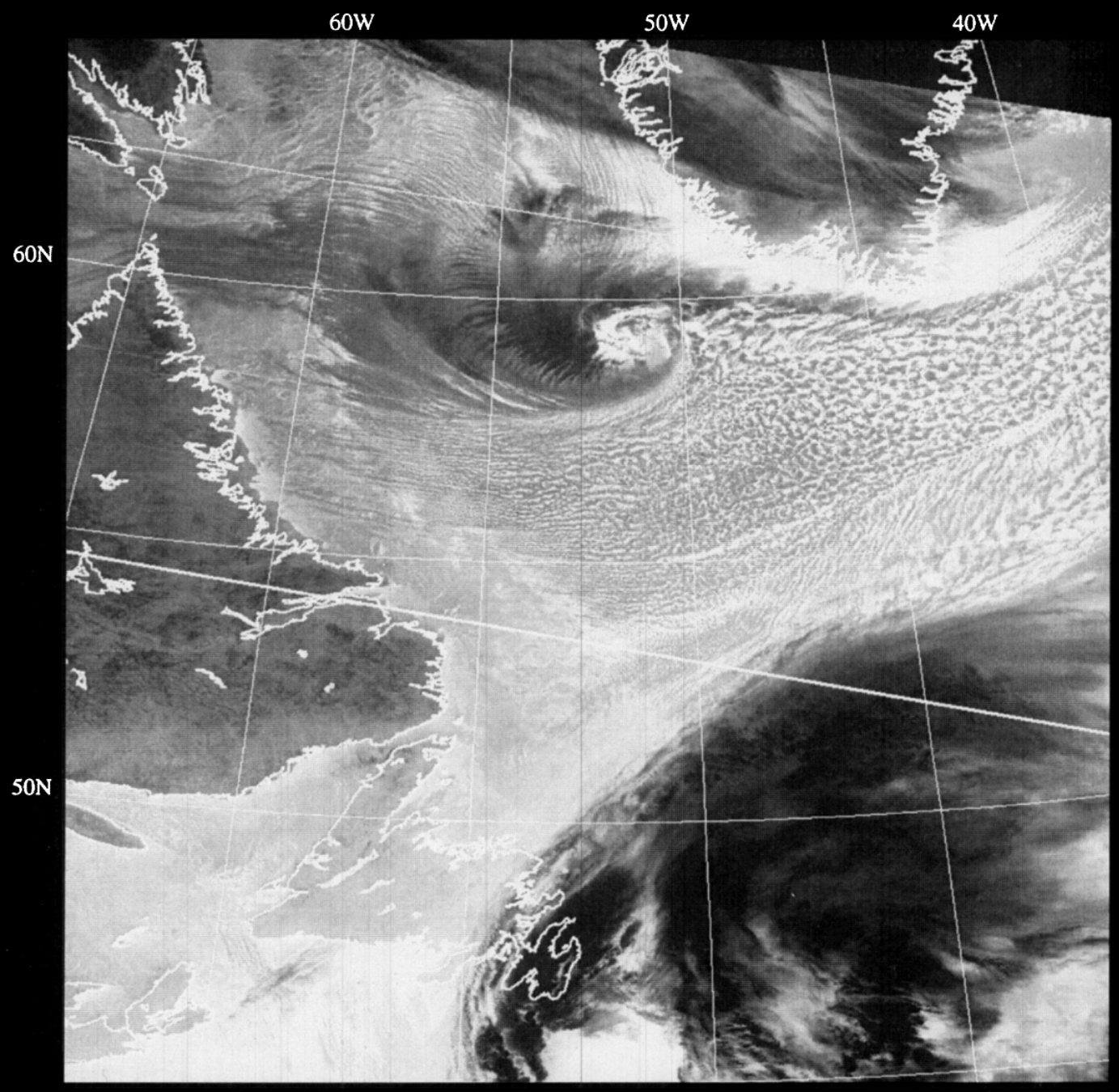

Fig. 5. IR image from the NOAA 11 pass at 07:03 GMT on 15 February 1992 showing the development of the polar low with its well defined eye. 
that on the southern flank of the cloud line, in the region of strong barotropic shear, there was a tongue of anomalously cold air that has penetrated to almost Cape Farewell. In the vicinity of the head of the cloud line, near $60^{\circ} \mathrm{N}, 55^{\circ} \mathrm{W}$, there was evidence of a weak dipolar anomaly with warmer air to the south and colder air to the north. $12 \mathrm{~h}$ earlier, the thickness field showed only the intrusion of the cold air; there was no indication of this dipole structure. The anomalously warm air to the south may have been an indication that latent heat release within the cloud had begun. In the figure, one can also see the circulation associated with the secondary synoptic low near $62^{\circ} \mathrm{N}, 38^{\circ} \mathrm{W}$. At this time, its central pressure was analysed to be near $970 \mathrm{mb}$. One can also see the cirrus outflow over Newfoundland associated with a synoptic low that was propagating northwards into the area of interest.

Fig. 5 shows the NOAA 11 image from the pass at 07:03 GMT on 15 February 1992. Over the fourteen hours from the time of the image in Fig. 4, a mesoscale vortex or polar low had developed along the cloud line. It appears that the low developed in the vicinity of the dipolar anomaly in the thickness field shown in Fig. 4. This view is supported by the imagery received from a NOAA 9 pass at 20:32 GMT on 14 February 1992. The well defined eye of the low is apparent near $58^{\circ} \mathrm{N}$, $52^{\circ} \mathrm{W}$. To the west of the eye, a wave pattern had developed at upper-levels that is suggestive of a horse's mane. This sort of wave pattern has also been noted in other studies of polar lows (Rasmussen and Aakjær, 1989) and has been attributed to the presence of gravity waves excited by the presence of a layer in which there is strong vertical shear in the horizontal wind field. For the first time in its evolution, there was a discernible difference in the height of the clouds associated the low. To the west of the eye, the cloud top temperatures were on the order of $-45^{\circ} \mathrm{C}$, while those to the east were on the order of $-40^{\circ} \mathrm{C}$. The higher clouds to the west of the storm suggest that deep convective activity was now underway in this sector. At this time, the disturbance was asymmetric with a north-south scale of approximately $300 \mathrm{~km}$ and an east-west scale of approximately $400 \mathrm{~km}$. The well-defined cloud field associated with the synoptic low propagating into the area of interest from the southwest is also evident. Indeed, this figure provides a rather dramatic example of the marked difference in scales that exists between synoptic and mesoscale lows.

Fig. 6 shows an IR image from a NOAA 12 pass at 13:00 GMT on the 15th. Overlaid on the image is the SSM/I derived ice scattering index, S85, from the F10 pass at 13:35 GMT on the 15th. It should be noted that this pass was not an overhead one and as a result, one does not have complete coverage over the area of interest. This accounts for the coarser resolution near the eastern edge of the pass. At this time, there was a well defined eye completely surrounded by a wall of convective clouds. As discussed previously, large values of the S85 index provide an indication of the presence of deep convection. From this figure one can see that high values of the index occurred in the cloud field associated with the polar low. The highest values, in excess of 8 , were coincident with the region of colder cloud top temperatures to the west of the eye. This supports the contention that deep convective activity was occurring in the region. It is interesting to note that on the previous day, the S85 index values associated with the organizing cloud line were on the order of 2. Missing SSM/I data from the night of the 14th and early morning of the 15 th implies that unfortunately one cannot use this index to determine the time of the onset of the deep convection more precisely.

The SSM/I retrieval for surface wind speed for the same F10 pass indicated a region of very high wind speed, in excess of $22 \mathrm{~m} / \mathrm{s}$, in the same region in which the deep convection was occurring. The ambient surface wind speed in the vicinity of the low and in the eye at this time was approximately $16 \mathrm{~m} / \mathrm{s}$. These high wind speeds have the potential to be slightly misleading in that the Labrador Sea is a region in which there are always strong offshore winds during winter. One can get an appreciation of the extreme nature of the winds associated with this polar low by considering that the mean surface wind speed in this area, as determined from a consideration of all F10 passes during the period 1 February to 15 March 1992, was $10 \mathrm{~m} / \mathrm{s}$ while the standard deviation was $4 \mathrm{~m} / \mathrm{s}$. One can therefore see that the wind speeds attained during the mature phase of the low were 3 standard deviations above the mean. The only other time during this period when wind speeds of this magnitude were attained in the Labrador Sea was during the passage of the rapidly deepening synoptic cyclone that preceded this event. 


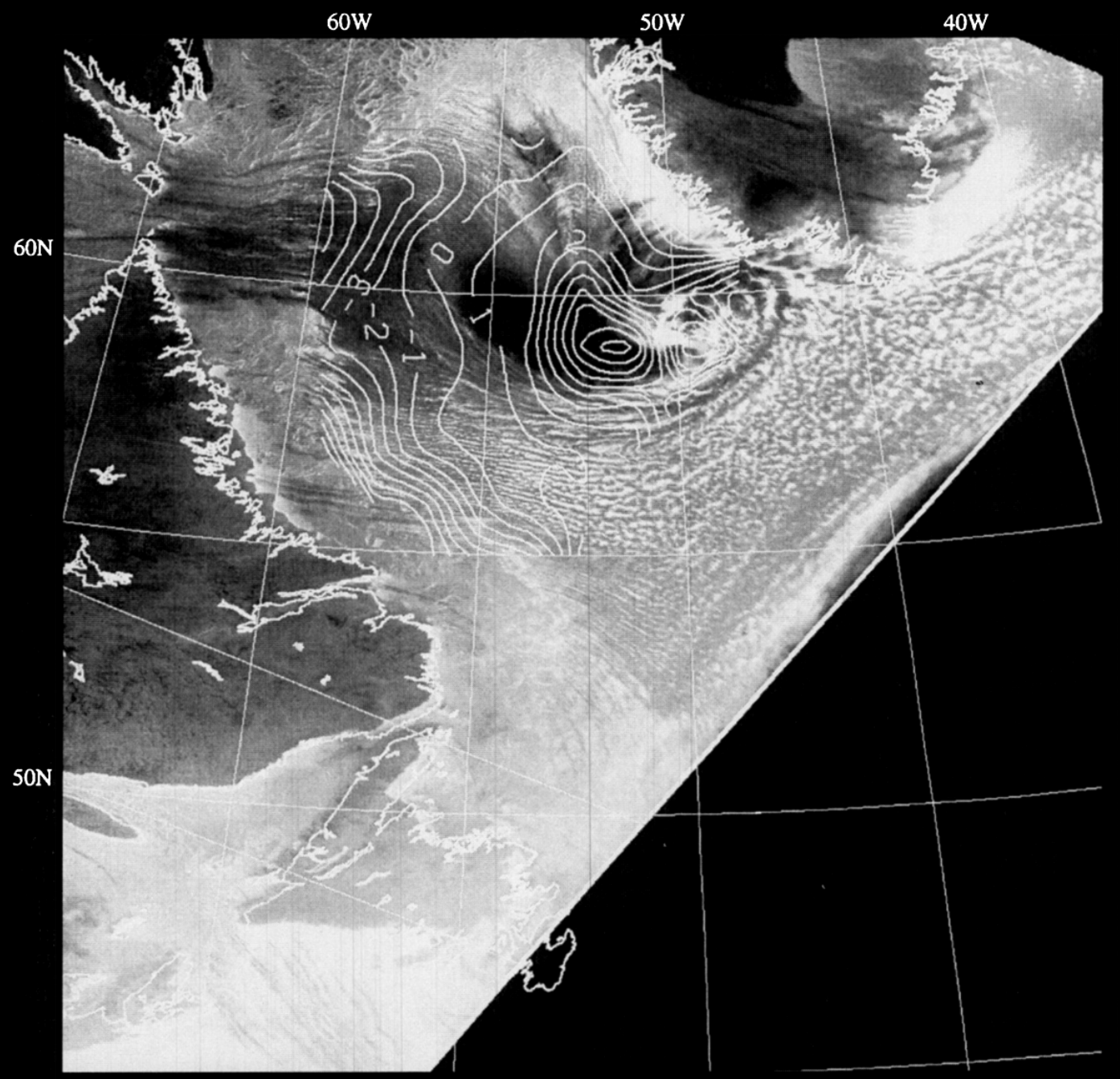

Fig. 6. IR image from the NOAA 12 pass at 13:00 GMT on 15 February 1992 showing the polar low in its mature state. Overlaid on the image is the SSM/I S85 index as determined from the F10 pass at 13:35 GMT on 15 February 1992.

Fig. 7 shows an IR image from the NOAA 11 pass at 16:50 GMT on 15 February 1992. Overlaid on the image is the $1000-500 \mathrm{mb}$ geopotential thickness field derived from the TOVS data for this pass. A comparison with Fig. 6 shows that the low was now symmetric with a horizontal scale of approximately $500 \mathrm{~km}$. From this figure, one can see that extensive low-level clouds had developed over the ice covered Hudson Strait, the strait that separates the Ungava Peninsula from Baffin
Island. They were presumably the result of an accelerated flow at low levels that increased the amount of heat that could be extracted from the surface. In this region, the cloud top temperature were on the order of $-39^{\circ} \mathrm{C}$, while the underlying ice was at $-29^{\circ} \mathrm{C}$. The TOVS derived thickness field is rather complicated. To the west of the center of the low, one can see evidence of the finger of cold air identified in Fig. 4. In the vicinity of the low itself, one can see a dipolar structure with the 


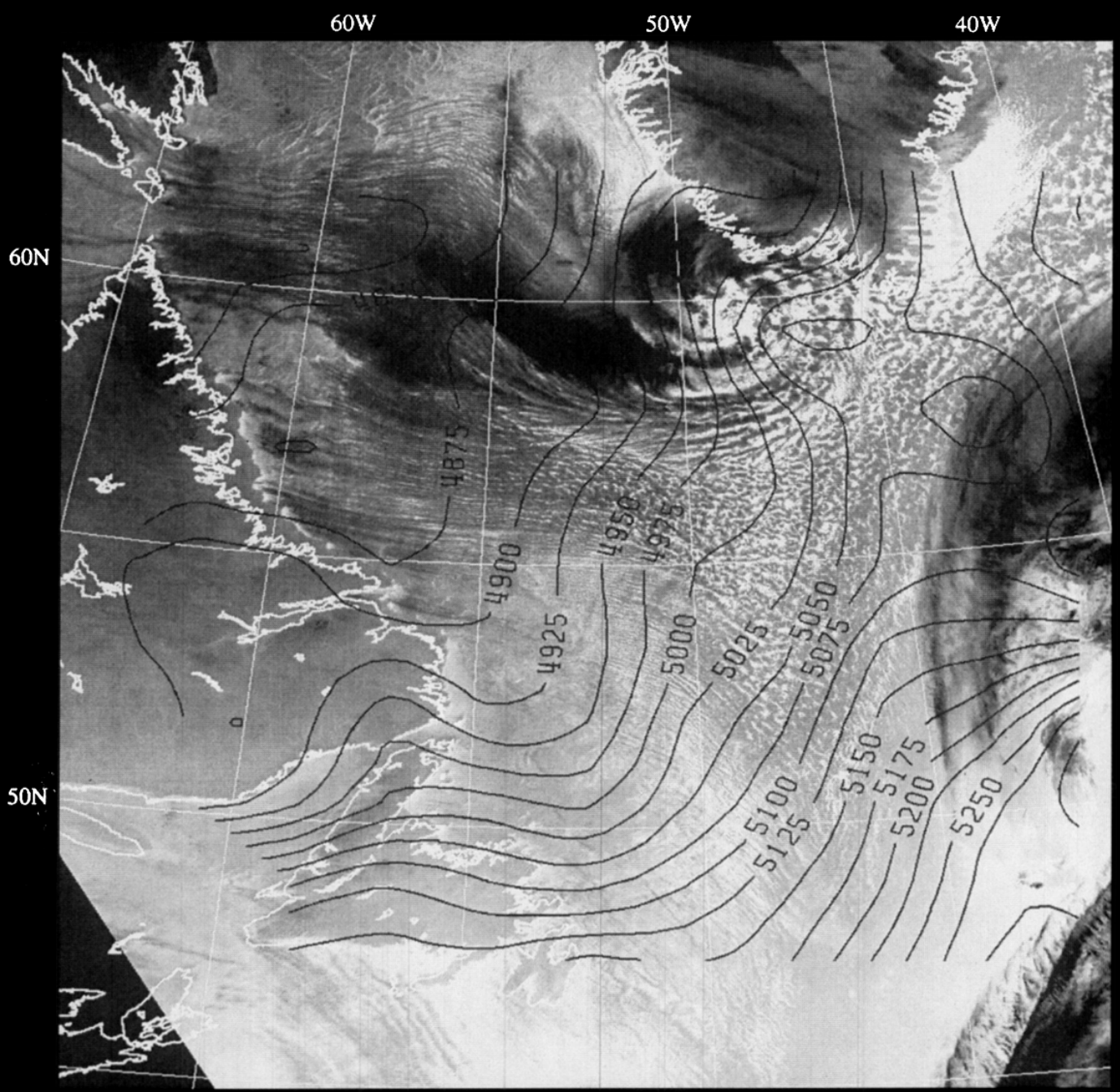

Fig. 7. IR image from the NOAA 11 pass at 16:50 GMT on 15 February 1992 showing the polar low in its mature state. Overlaid on the image is the TOVS derived $1000-500 \mathrm{mb}$ geopotential thickness $(\mathrm{m})$ for the same pass.

cold air to the south of the eye and the warm air to the north. This segregation is consistent with the idea that this system was baroclinic in origin.

From Fig. 2d, the ECMWF analysed mean sea level pressure and $10 \mathrm{~m}$ winds at 18 GMT on 15 February 1992, one can see that the analysis failed to capture the evolution of the polar low. However, there was the indication of a weak trough present in the area in which the low developed. In the same region, there was also evidence of a weak cyclonic circulation with a magnitude of approximately $0.6 f$. The synoptic low that had propagated into the area had an analysed central pressure of approximately $977 \mathrm{mb}$. It was in the midst of an explosive deepening. Over the $24 \mathrm{~h}$ from $6 \mathrm{GMT}$ on the 14 th, its central pressure had dropped by $30 \mathrm{mb}$.

The polar low decayed rapidly as it rounded Cape Farewell. Its decay was undoubtedly accelerated by the presence of the region of strong deformation between the synoptic low and Greenland. Fig. 8 shows an IR image from the NOAA 11 


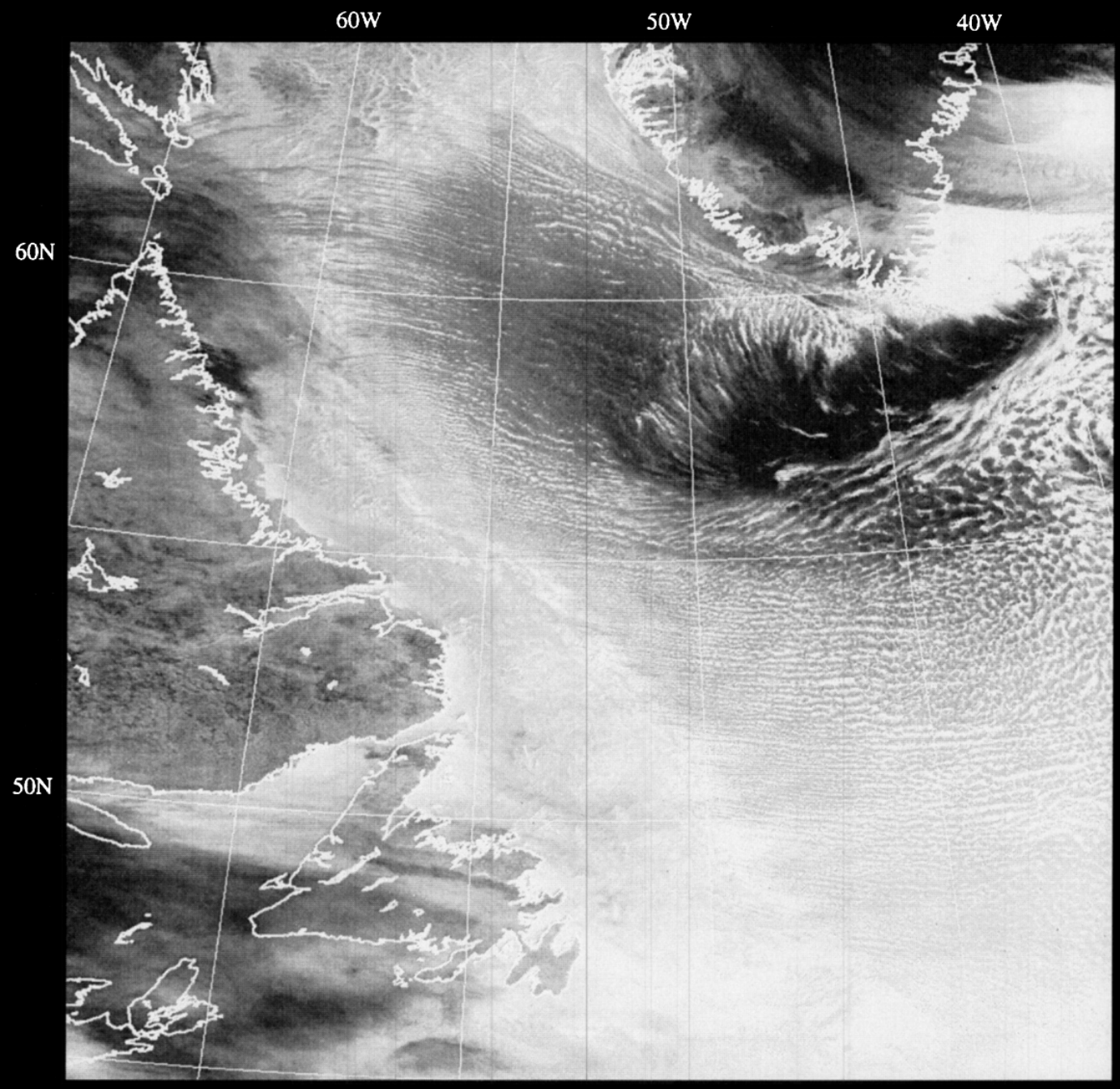

Fig. 8. IR image from the NOAA 11 pass at 06:48 GMT on 16 February 1992 showing the cloud field that remained after the decay of the polar low.

pass at 06:48 GMT on the 16th. From this figure, one can see that all that is left of the polar low is the extensive region of high clouds with cloud top temperatures of $-50^{\circ} \mathrm{C}$ to the east of Cape Farewell. No evidence of any circulation associated with the polar low is evident from this figure. At this time, the synoptic low was located near $63^{\circ} \mathrm{N}, 38^{\circ} \mathrm{W}$ and had attained its deepest analysed pressure of $960 \mathrm{mb}$. Over the next $24 \mathrm{~h}$, it continued to propagate up the east coast of Greenland and eventually dissipated around 18 GMT on the 17 th.

\section{Mechanism(s) responsible for the genesis of the polar low}

The vast majority of polar lows that develop in the Norwegian Sea are generally recognized to result from an interaction of a shallow baroclinic zone that forms along the sea-ice edge and a upperlevel vorticity maxima (Reed, 1986; Nordeng, 1990; Rasmussen et al., 1992). In the vernacular of the school of "IPV analysis" (Eliasen and Kleinschmidt, 1957; HMR; Thorpe, 1993), one can think of this as being an interaction between 
an upper-level IPV anomaly and a low-level surrogate $\mathrm{PV}$ anomaly resulting from the differential heating that occurs across the sea ice edge (Reed, 1991; Rasmussen et al., 1992).

In Fig. 9, the isentropic potential vorticity and winds in the 290:300 $\mathrm{K}$ layer are shown at 4 times over the time period that bracketed the life-cycle of the polar low. Also indicated is the line used to calculate the vertical sections to be discussed later. From this figure one can see that during this time

(a) 18 GMT, Feb. 131992

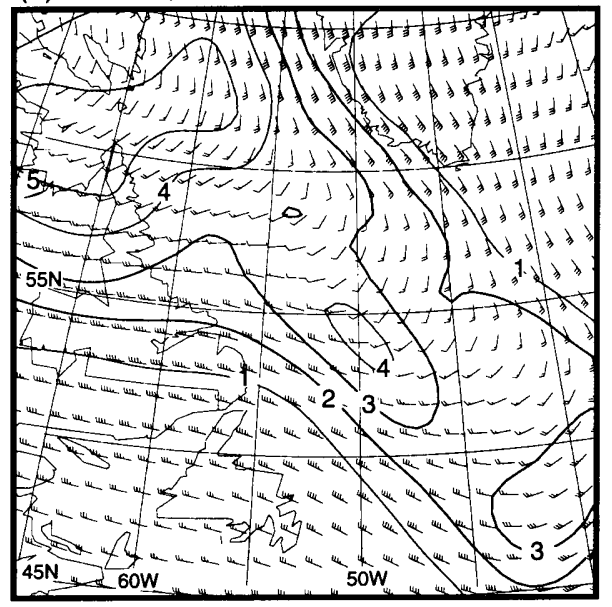

(c) 06 GMT, Feb.15 1992

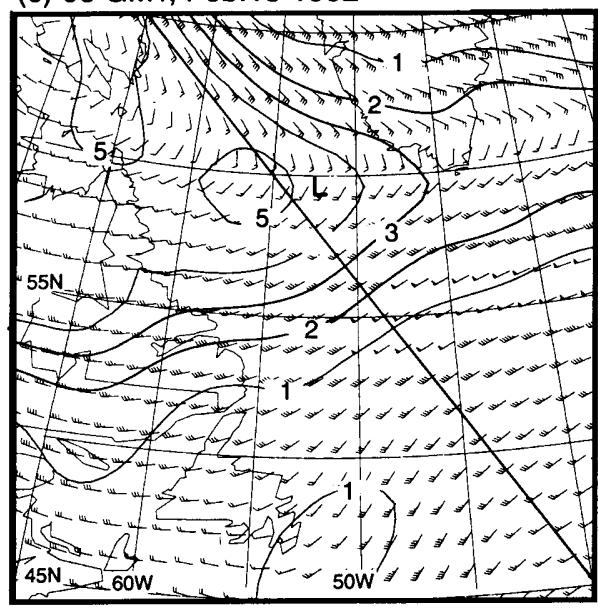

period, a ridge of high IPV air was situated over the area of interest. The core of this anomaly was characterized by potential vorticities on the order of $5 \mathrm{PV}$ units. During the period from $18 \mathrm{GMT}$ on the 13th to 6 GMT on the 16th the axis of the ridge underwent a counter clockwise rotation of approximately $45^{\circ}$. That is the ridge's orientation went from being in the northwest-southeast direction to being in the west-east direction. Associated with this change in orientation was the south

(b) 18 GMT, Feb. 141992

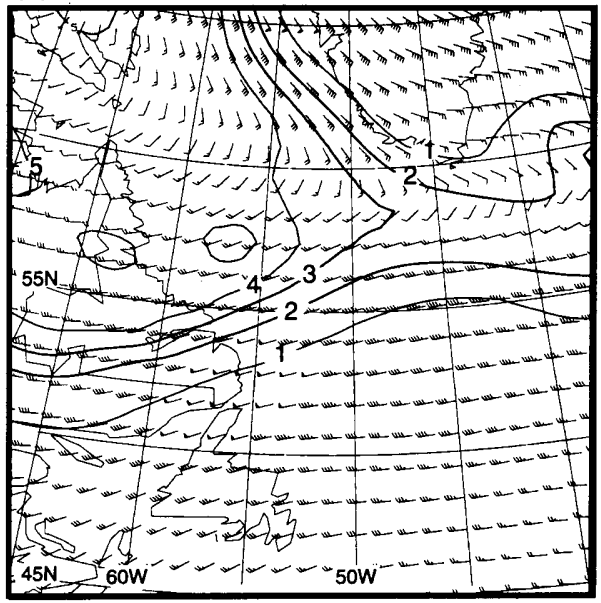

(d) 06 GMT, Feb.16 1992

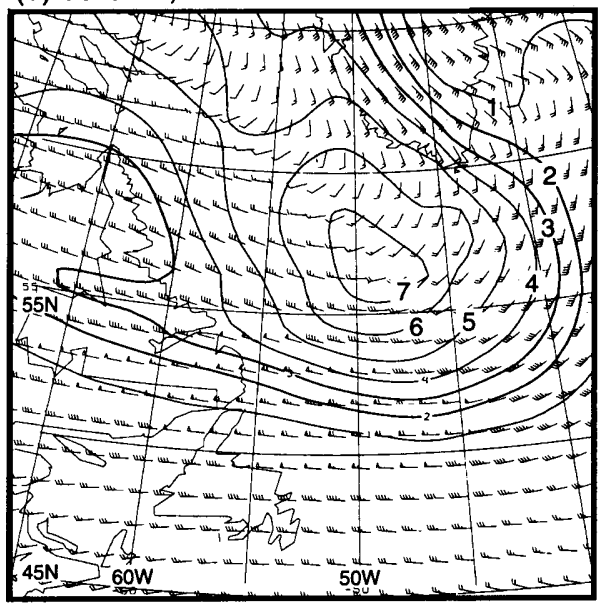

Fig. 9. Isentropic potential vorticity (PV units) and winds (m/s) on the 290:300 K layer as analysed by the ECMWF for 4 times during the life-cycle of the polar low: (a) 18 GMT on 13 February 1992, (b) 18 GMT on 14 February 1992 , (c) 06 GMT on 15 February 1992, and (d) 06 GMT on 16 February 1992. The 2 and 3 PV unit contours have been highlighted with a heavier line to denote the approximate location of the tropopause. The location of the crosssections displayed in Figs. 12, 13 and 14 is indicated in panel (c). The location of the polar low is indicated by the "L" in panel (c). 
eastward movement of the core of the anomaly. At 18 GMT on the 13th, it was situated over the Hudson Strait. By 06 GMT on the 15th, Fig. 9c, it was situated at approximately at $60^{\circ} \mathrm{N}, 55^{\circ} \mathrm{W}$, just to the west of the location indicated with an "L" where the polar low was developing.

Over the next $24 \mathrm{~h}$, a very large IPV anomaly of magnitude $7 \mathrm{PV}$ units was advected into the area from the west. This second anomaly was associated with the synoptic low that tracked into the area from Newfoundland and that contributed to the demise of the polar low. As expected, the ridge of high potential vorticity air was associated with a cyclonic circulation. The maximum relative vorticities in the 290:300 $\mathrm{K}$ layer reached $1.0 \mathrm{f}$. The role, if any, that the Greenland Plateau played in the channelling of this IPV anomaly is a subject that is worthy of further investigation. Indeed, the presence of significant topography to the east is perhaps the most important characteristic that distinguishes mesoscale cyclogenesis in the Labrador Sea from similar events that occur in the Norwegian Sea.

As discussed by HMR and others, the existence of IPV anomalies are the result of intrusions of stratospheric air into the upper-level troposphere. Given that the stratospheric air has a high ozone concentration, it seems plausible that one should expect higher than usual amounts of ozone to be associated with these anomalies. Indeed several studies (Shapiro et al., 1982; Gyakum and Barker, 1988; Mote et al., 1991; Reader and Moore, 1995) have made use of TOMS total column ozone data to document this correlation. Notwithstanding the limitations discussed in Section 2, the TOMS data does provide some insight into the dynamical processes responsible for the development of the polar low. Fig. 10 shows the Grid-TOMS data for $13,14,15$ and 16 February 1992 . From this figure that one can see that on the 13th, there was a region with column ozone concentrations in excess of 460 Dobson units that was situated over the Hudson Strait. Over the next 4 days, this region propagated down over the Labrador Sea and on the 16th eventually formed a pool of high total column ozone air, 480 Dobson Units, to the south of Greenland. Also shown on Fig. 10b, the data for 14 February is the location where the polar low developed. One can see that it developed along the leading edge of the ridge of high column ozone. A comparison with Fig. 9 shows a broad qualita- tive agreement between the IPV and TOMS ozone fields. One should not of course expect total agreement as the IPV data is for a given layer in the atmosphere, while the TOMS data is for the total atmospheric column. Nevertheless, the correlation that exists between these two independent datasets provides added confidence that there was indeed an upper-level anomaly present over the Labrador Sea during the period in which the polar low developed.

An interesting question that will form the basis of a subsequent study is the following: Was the presence of column ozone values of this magnitude an anomalous event? A partial answer to this question comes from a computation of the mean and standard deviation of total column ozone over the Labrador Sea for the month of February 1992 from the TOMS data. The mean value was approximately 410 Dobson Units while the standard deviation was approximately 30 Dobson Units. One can thus see that the values attained during the period during which the polar low developed were approximately 2 standard deviations above the mean. This provides one with some confidence that this was indeed an anomalous event. It is interesting to note that even higher values of total column ozone (in excess of 500 Dobson Units) were observed over the Labrador Sea at the end of February 1992. This occurrence was associated with a case of explosive cyclogenesis in which a $930 \mathrm{mb}$ low developed over the Labrador Sea (Reader and Moore, 1995).

As described above, it is possible to retrieve an estimate of total column ozone from the TOVS data. Fig. 11 shows this retrieval for four NOAA 11 passes that bracket the time period during which the polar low developed. Also indicated are the locations of the major cloud fields as deduced from the corresponding AVHRR imagery. A comparison with Figs. 9 and 10 show a high degree of qualitative agreement. One can again see the movement of a core of ozone rich air from a location over the Hudson Strait on the 13th, down over the Labrador Sea on the 14th and 15th and eastward past Cape Farewell on the 16th. Of particular interest is the situation at 17:01 GMT on the 14th, Fig. 11b. At this time, one can see that the ozone anomaly is situated directly over the linear cloud feature. As discussed above, it was during the 12-h period from approximately 18 GMT on the 14 th to 06 GMT on the 15 th that the polar 
(a) Feb. 131992

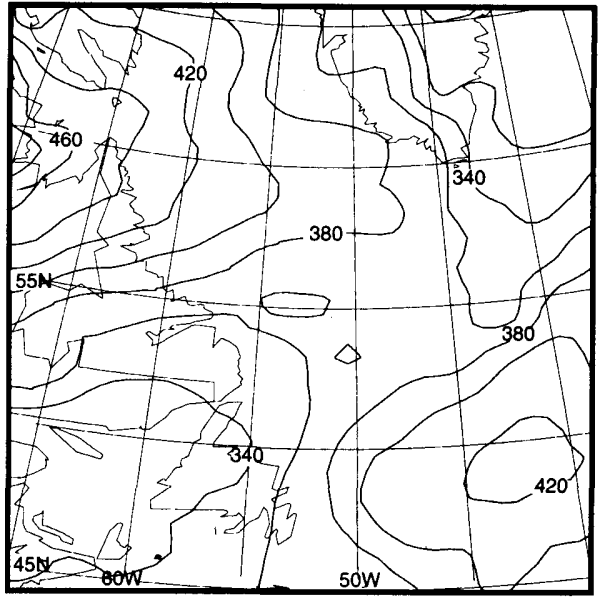

(c) Feb.15 1992

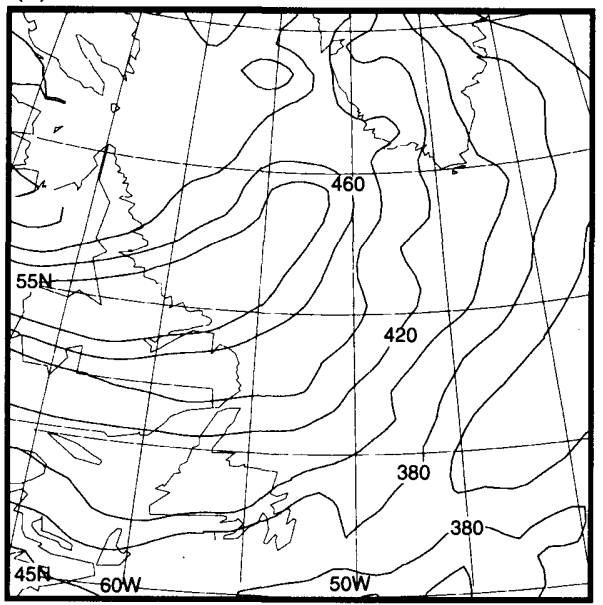

(b) Feb. 141992

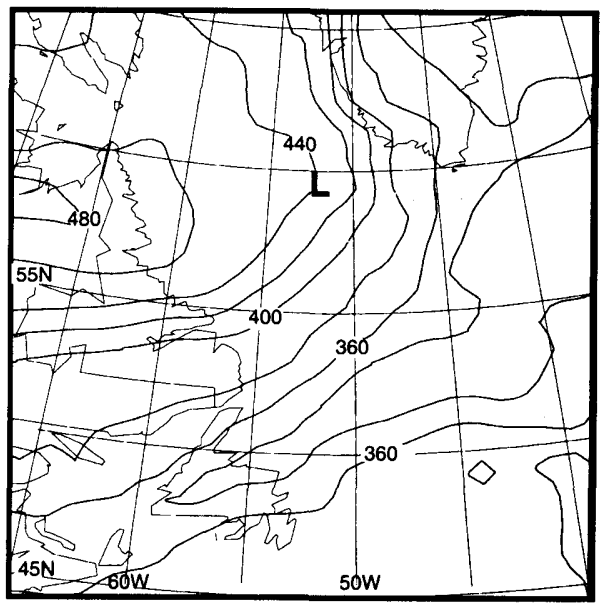

(d) Feb.16 1992

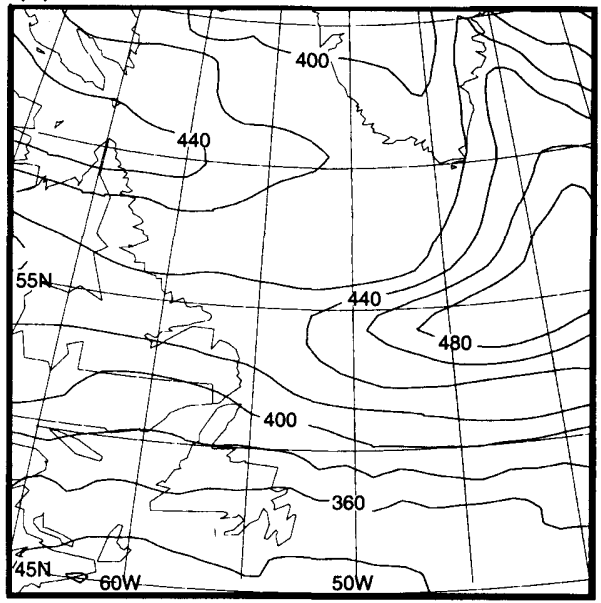

Fig. 10. Total column ozone (Dobson units) as determined from the TOMS data for 4 times during the life-cycle of the polar low: (a) 13 February 1992, (b) 14 February 1992, (c) 15 February 1992, and (d) 16 February 1992 . The location of the polar low at the time of the retrievals is indicated by the " $\mathrm{L}$ " in panel (b).

low underwent its initial baroclinic development phase. From Fig. 11b, one can therefore see that this initial stage of development was preceded by the arrival of the ozone anomaly, and presumably an upper-level potential vorticity anomaly, over the linear cloud feature.

There are some important discrepancies between the total column ozone amounts as deduced from the TOMS and TOVS instruments that should be commented upon. On the 13th, the TOVS retrieval shows a core of high ozone concentrations over the primary synoptic low. In contrast, the TOMS retrieval shows only a ridge of high ozone concentrations in the vicinity of the low. A similar disagreement is evident on the 16 th as well. The TOVS product also displays significantly more mesoscale structure in the ozone field than does the TOMS product. The smoothing that the TOMS data has been subject to undoubtedly played a rôle in producing these discrepancies. The possibility of cloud contamination is more problematic. In this regard it is interesting to note that the largest discrepancies between the two retrievals occurred in regions of extensive high cloud. It is for this reason 
(a) 17:17 GMT, Feb. 131992

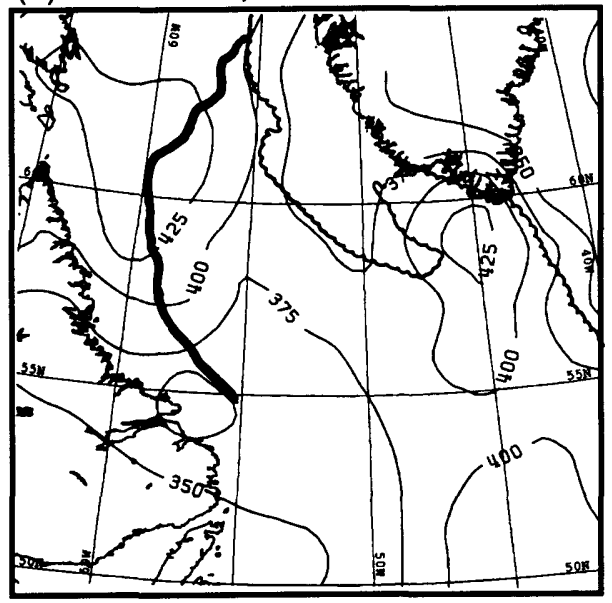

(c) 07:03 GMT, Feb.15 1992

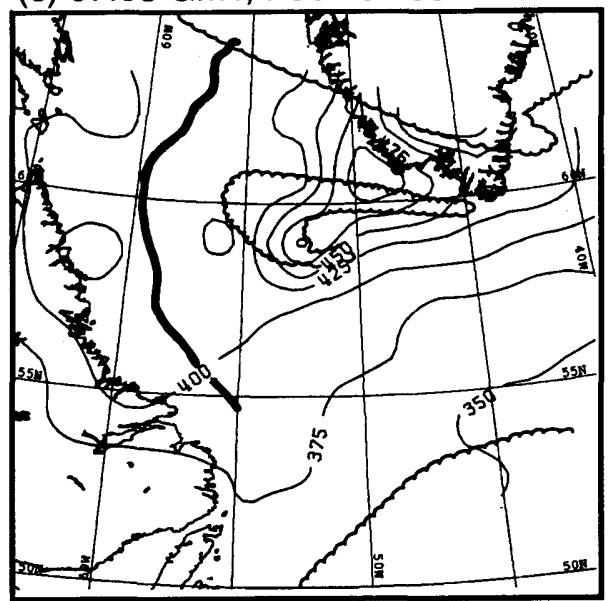

(b) 17:01 GMT, Feb. 141992

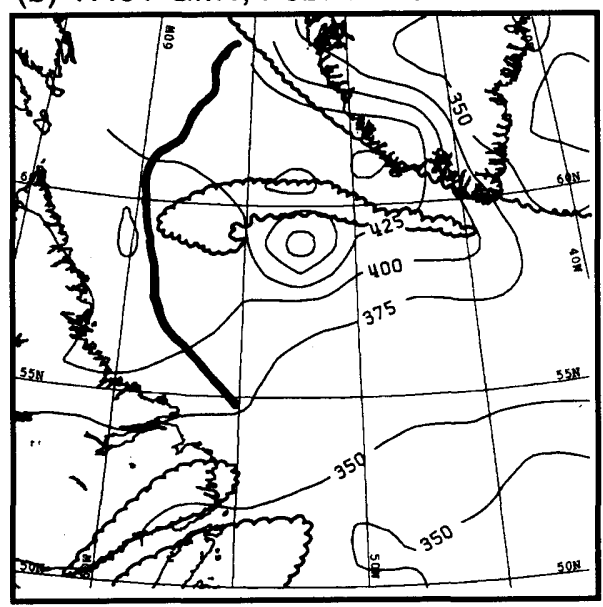

(d) 06:48 GMT, Feb.16 1992

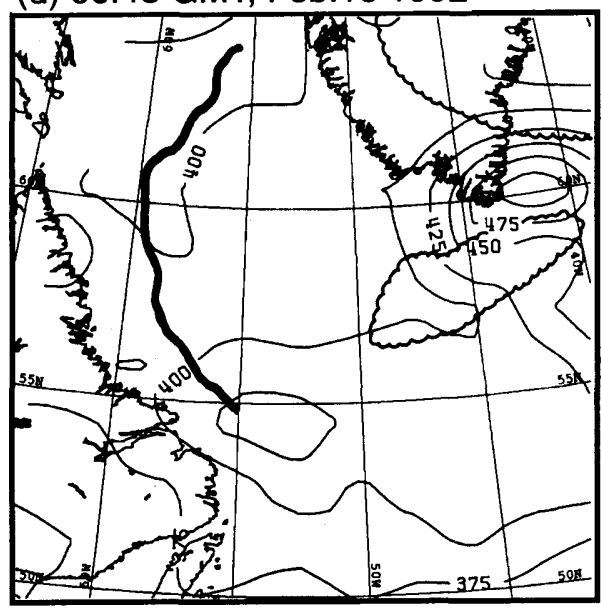

Fig. 11. Total column ozone (Dobson units) as determined from the TOVS data for 4 times during the life-cycle of the polar low: (a) 17:17 GMT on 13 February 1992, (b) 17:01 GMT on 14 February 1992, (c) 07:03 GMT on 15 February 1992, and (d) 06:48 GMT on 16 February 1992. The location of the major cloud fields, as derived from the corresponding AVHRR imagery, are denoted by the scalloped lines. The location of the ice edge is indicated by the solid line.

that one has the most confidence in the retrievals prior to the development of significant cloud features. Furtunately, it is this pre-development phase that is most interesting in that the TOMS and TOVS retrievals provide evidence, at least in this instance, of an upper-level circulation prior to any manifestation of it in the cloud field.

According to the conceptual model of HMR, one needs a low-level potential vorticity anomaly with which the upper-level anomaly can interact. There are numerous mechanisms that can produce such a low-level anomaly. In their conceptual model of cyclogenesis, HMR assume that it is induced along a preexisting low-level baroclinic zone by the arrival of the upper-level potential vorticity anomaly. This scenario follows the work of Bretherton (1966) who showed that a positive surface temperature anomaly can be regarded as a surrogate low-level potential vorticity anomaly. Reed (1991) points out that diabatic processes, such as latent heat, can also produce low-level potential vorticity anomalies. In this instance 
one actually generates a dipolar anomaly with enhanced values of potential vorticity below the height of maximum heating and reduced values above.

Fig. 12 shows a vertical cross-section of the ECMWF analysed potential temperature, potential vorticity and normal component of the wind fields at 06 GMT on the 13th along the line indicated in Fig. 9c. At this time, one can see the shallow baroclinic zone generated by differential surface heating across the sea-ice edge. One can also see evidence of a much broader and deeper baroclinic zone associated with the polar front. An integral component of this synoptic scale front was the presence of the upper-level jet core near $300 \mathrm{mb}$. The potential vorticity field was quite complex. Below $700 \mathrm{mb}$, there was a dipolar anomaly in the potential vorticity field with a layer in which the anomaly was negative overtop a surface layer in which it was positive. Above $700 \mathrm{mb}$, the potential vorticity field was dominated by the presence of the upper-level jet core. Over the shallow ice-edge front, it was for the most part featureless. The dipolar low-level structure in the potential vorticity field is consistent with the idea that condensational heating was occurring in the lower troposphere. This heating was presumably associated with the streamers of low-level clouds that are characteristic of the Labrador Sea at this time of year. An example of these clouds, at a slightly later time, can be seen in Fig. 1.

As described in Section 3, a deep and intense synoptic scale low propagated into the Labrador Sea over the next $18 \mathrm{~h}$. In its wake, a cold air outbreak occurred that resulted in a significant increase in wind speed and a concomitant increase in the magnitude of the fluxes of sensible and latent heat. Maximum surface fluxes, as diagnosed from the ECMWF analysis, during this cold air outbreak were on the order of $700 \mathrm{~W} / \mathrm{m}^{2}$. Fig. 13 shows a vertical cross-section, along the same line as in Fig. 12, of the ECMWF analysed potential temperature, potential vorticity and normal component of the wind fields at 06 GMT on the 14th. A comparison with Fig. 12 yields several interesting changes. Most notably, the strong surface fluxes have acted to destabilize the entire layer below $700 \mathrm{mb}$ and by so doing have removed the surface positive potential vorticity anomaly. This is quite similar to the result obtained by Moore (1990). In that study, the problem of the modifica- tion of an existing baroclinic zone by surface fluxes was considered. It was found that the fluxes acted to produce a low-level negative potential vorticity anomaly. At upper-levels, one can also see that the core of the jet stream has moved northwards.

Fig. 14 shows a vertical cross-section, along the same line as in the two preceding figures, of the ECMWF analysed potential temperature, potential vorticity and normal component of the wind fields at $18 \mathrm{GMT}$ on the 14th. As discussed above, this was just prior to the time period during which the polar low developed. At low-levels, one can again see the development of a dipolar potential vorticity anomaly similar to that in Fig. 12 . One can also see that the largest baroclinicities were associated with the polar low to the south rather than the ice-edge front to the north. At upperlevels, one can for the first time see the signature of the upper-level potential vorticity that is hypothesised to play a rôle in triggering the development of the polar low. A comparison of Figs. 13 and 14 show that the presence of this anomaly was associated with the southerly advection of cold air aloft. One can also see the pronounced cyclonic circulation at upper-levels that was associated with the anomaly. As indicated on the figure and described previously, the low developed in the vicinity of the anomaly.

If one attempts to apply the conceptual model of HMR described above to this case there is at first glance some obvious difficulties. Most striking is that the ECMWF analysis shows a negative potential vorticity anomaly at the surface. Indeed the potential temperature field at this time shows a remarkable qualitative similarity to that presented in HMR for the case of a negative surface temperature anomaly (HMR: Fig. 16b). At upperlevels, one has good agreement with HMR. That is one has a positive potential vorticity anomaly with its associated cyclonic circulation.

The resolution of this conundrum most likely comes from the realization that the ECMWF analysis was unable to resolve the convective heating that occurred along linear cloud feature that developed into the polar low. As described above, this sort of heating would result in the development of a narrow dipolar potential vorticity anomaly centered about the level of maximum heating. Furthermore, the TOVS retrieved thickness field at this time, Fig. 7, shows considerably more baroclinicity was present than was captured 

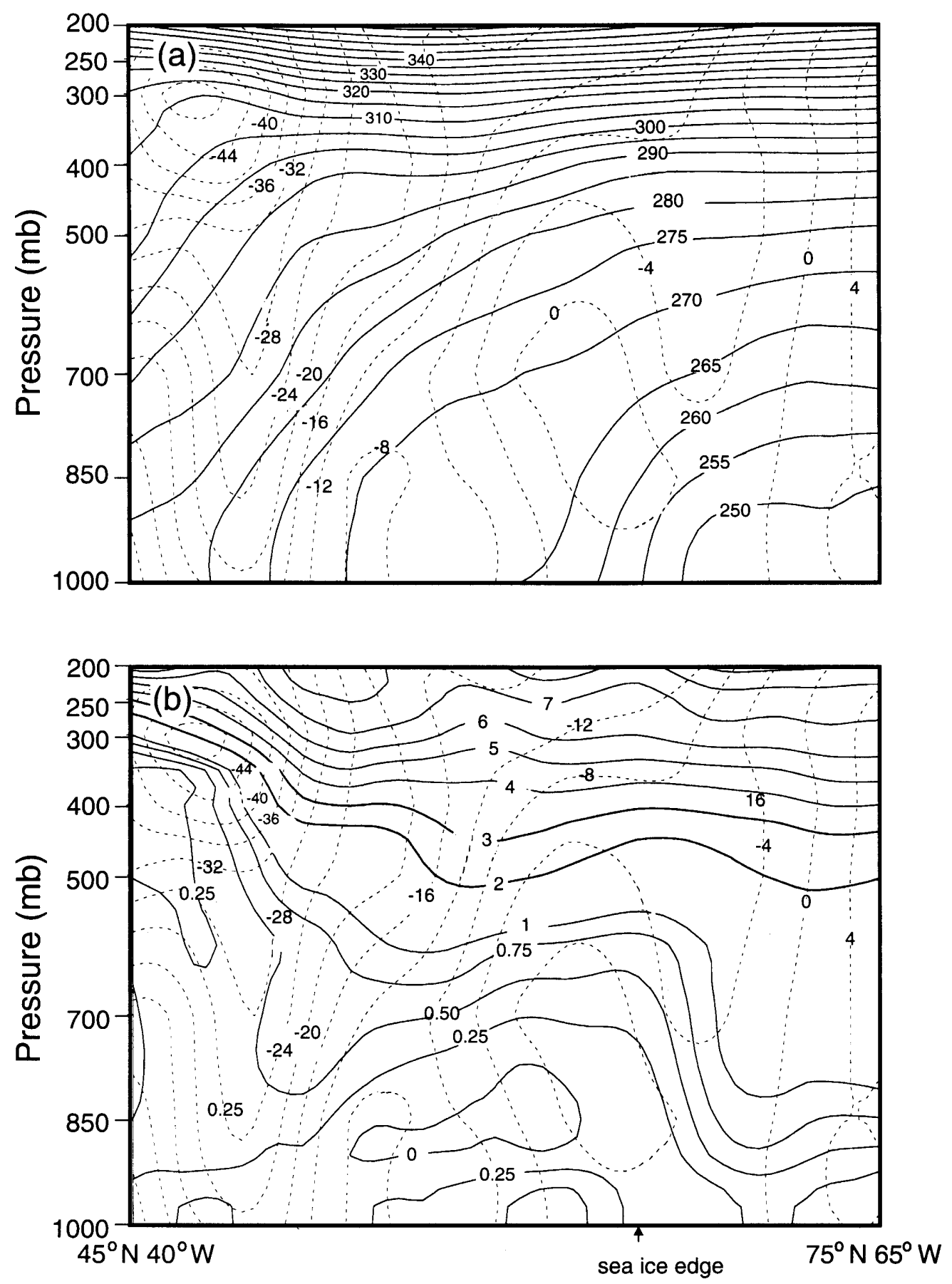

Fig. 12. Cross-sections, along the line indicated in Fig. $9 \mathrm{c}$, of potential temperature $\left({ }^{\circ} \mathrm{C}\right)$ and normal component of wind $(\mathrm{m} / \mathrm{s})(\mathrm{a})$ and potential vorticity (PV units) and normal component of wind $(\mathrm{m} / \mathrm{s})(\mathrm{b})$ as analysed by the ECMWF at 06 GMT on 13 February 1992. The location of the sea-ice edge is indicated. 

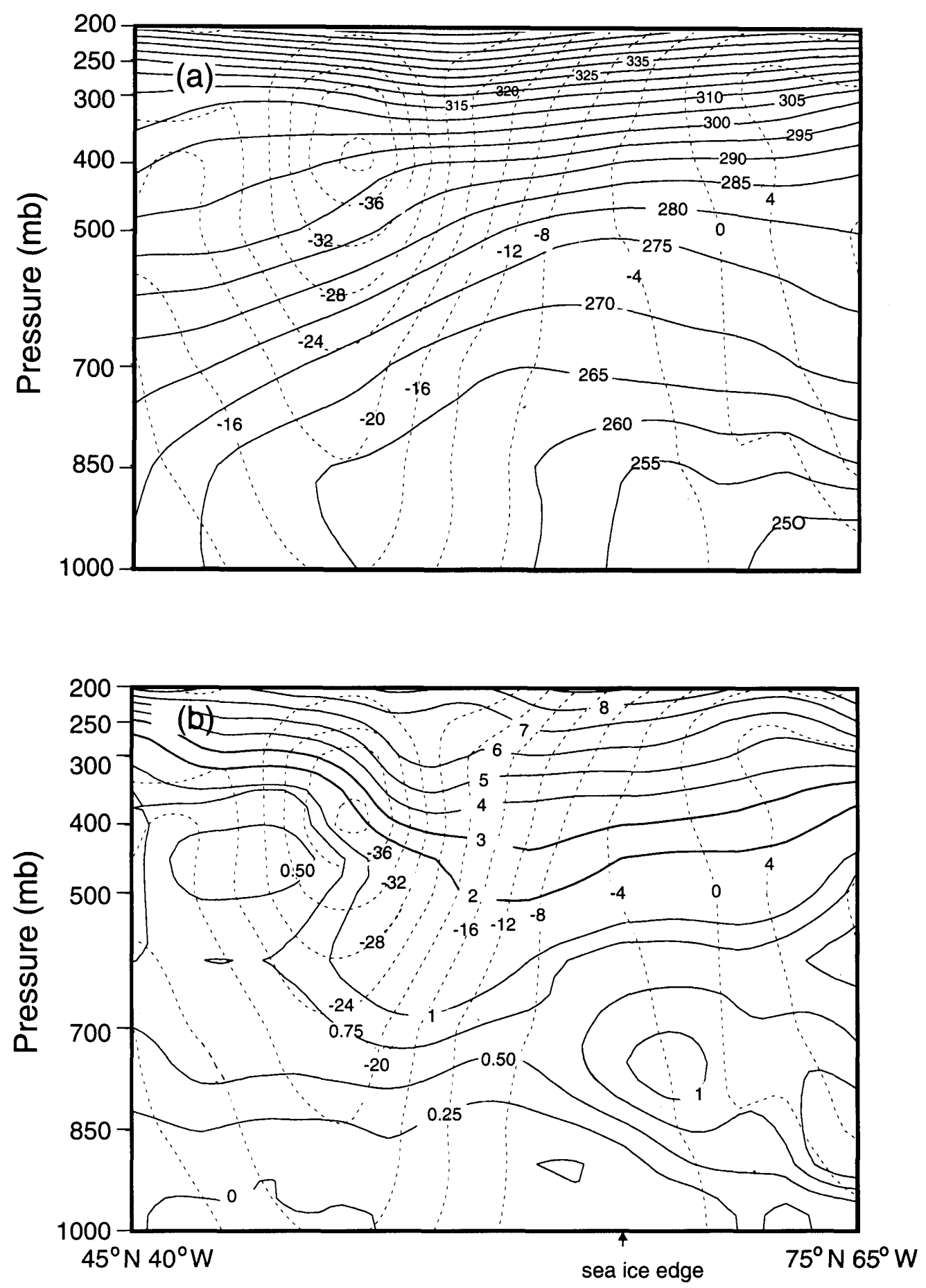

Fig. 13. As in Fig. 12 but for 06 GMT on 14 February 1992. 

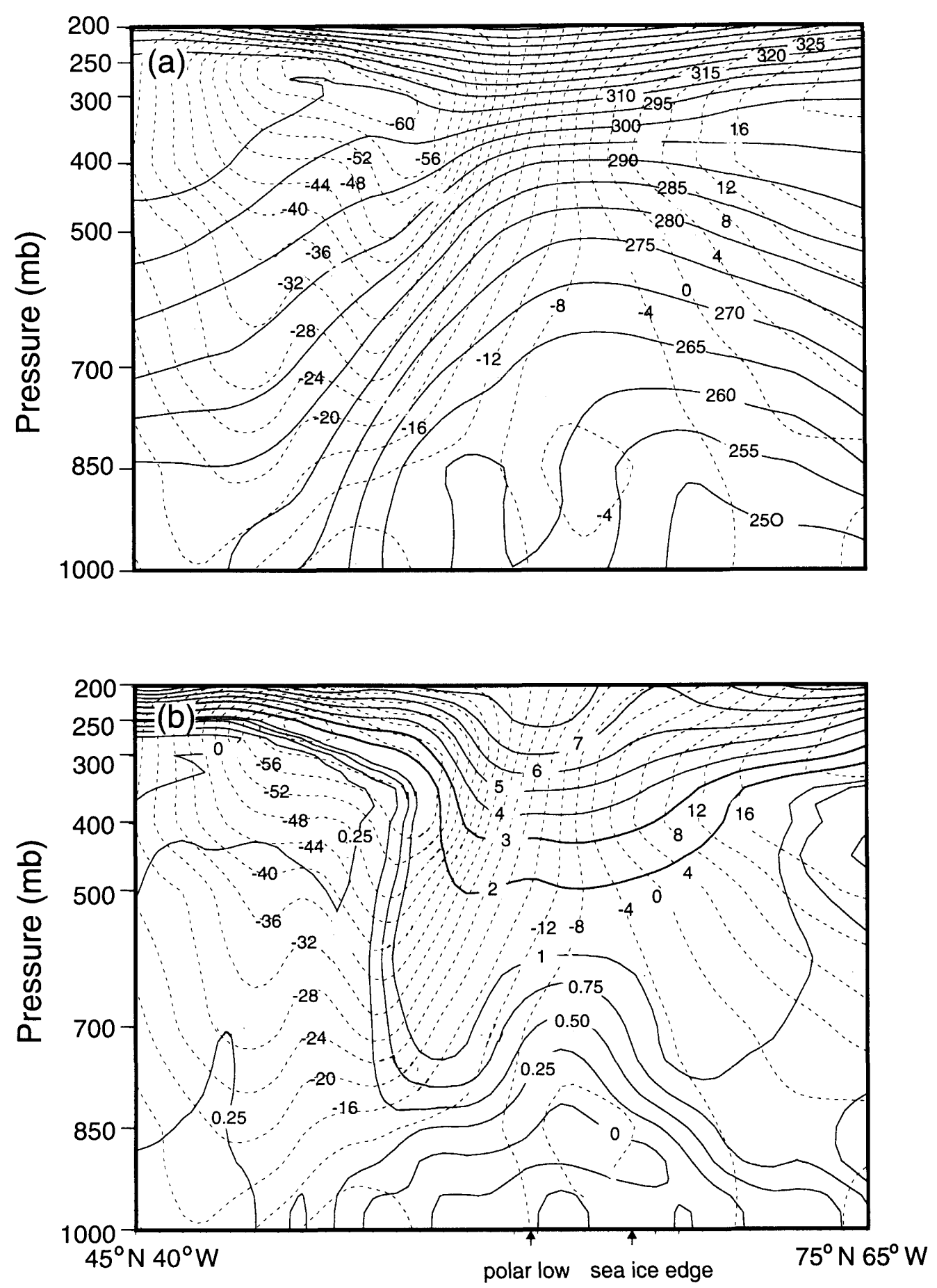

Fig. 14. As in Fig. 12 but for 18 GMT on 14 February 1992. The location where the polar low developed is indicated. 
by the ECMWF analysis. These two factors could in principle produce a positive surface potential vorticity anomaly of sufficient magnitude to couple with the upper-level anomaly.

The penetration depth of the anomalies is on the order of the Rossby height (HMR) given by $f L / N$, where $L$ is the horizontal scale of the anomaly, $N$ is the Brunt-Väisälä frequency and $f$ is the Coriolis parameter. In this regard the very weak stratification over the Labrador Sea, Brunt-Väisälä frequencies of the order of $6 \times 10^{-3} \mathrm{~s}^{-1}$, evident in Figs. 12-14 allows for large penetration depths. From Figs. 9-11, the upper-level anomaly has a horizontal scale of the order of $500 \mathrm{~km}$. This results in a penetration depth on the order of $8 \mathrm{~km}$. This is sufficiently large so as to allow the upperlevel anomaly to interact with the surface anomaly.

As the ECMWF analysis was unable to capture the development of the polar low, cross-sections at later times will be not shown.

\section{Summary and discussion}

In this paper, we have presented a case study of the development and structure of a Labrador Sea polar low that developed during February 1992. As there is unfortunately no in-situ data available, we have relied upon data from satellite based platforms as well as the high resolution objective analysis from the ECMWF. Although the ECMWF analysis was unable to capture the development of the low itself, it was nevertheless able to identify several key features associated with its development. The analysis of this event bears a strong resemblance to what was observed by Rasmussen and Purdom (1992) in their report on a Labrador Sea polar low event during 1989.

This study has identified several complex interactions between processes occurring on the synoptic scale, mesoscale and cloud scale that contributed to the development of the polar low. It developed along a linear mesoscale cloud band that appeared after the passage of a deep and intense synoptic scale low through the Labrador Sea. From the satellite imagery, it appears that the cloud band originated just offshore of the coast of Labrador in the lee of the Torngat Mountains. Recently, Rasmussen et al. (1995) have reached similar conclusions regarding the role that the upstream environment plays in the initiation of cloud band. The cloud band first appeared as a rather amorphous feature that underwent a rather striking transformation into a well defined linear feature as it propagated out into the Labrador Sea. It is conjectured that this organization was the result of cloud scale processes such as CISK. Although not captured by the ECMWF analysis, the heating associated with the convection along the cloud band undoubtedly produced a low-level potential vorticity anomaly along the band. The ECMWF analysis indicated that an upper-level potential vorticity anomaly was present prior to the development of the low. The anomaly was associated with a marked increase in total column ozone over the Labrador Sea that was identified in both the TOVS and TOMS data. The amount of ozone present during this time period exceeded climatological values by more than two standard deviations. Signatures of the anomaly were also present in other TOVS derived fields. The polar low developed just after the upper-level anomaly passed over the cloud band. It thus appears to have been a cyclogenesis event of the sort described by HMR.

The low went through a two stage life-cycle. The first phase appeared to have been baroclinic in nature and resulted directly from the interaction of the two anomalies. During this phase, the polar low was an asymmetrical disturbance with uniform cloud heights. A well defined eye developed during this phase. No evidence of deep convection was present in the SSM/I derived S85 index. During the 2 nd phase, the low became more symmetric in structure and deep convective clouds appeared southwest to the eye. Large values of the S85 index occurred in this region, supporting the contention that deep convection was occurring at this time. It was during this time that SSM/I derived surface wind speeds in excess of $22 \mathrm{~m} / \mathrm{s}$ were observed. The magnitude of the wind speeds observed was more than three standard deviations above the mean for the month of February 1992.

The low dissipated into a linear cloud pattern as it rounded the tip of Greenland. Its rapid demise may have been aided by the presence of a deformation field associated with a large synoptic scale cyclone that passed to the east of Greenland during this time.

In many ways, the evolution of this low was similar to what is observed to occur in the Norwegian Sea. In particular the two stage evolu- 
tion with strong upper-level support is reminiscent of what appears to be a characteristic of polar lows off Norway (Rasmussen, 1985; Rasmussen et al., 1992). There are, however, some differences. Most notably, polar lows in the Norwegian Sea area do not appear to originate along linear cloud bands. In addition, they appear to develop along the shallow fronts associated with the sea-ice edge (Rasmussen et al., 1992) while those in the Labrador Sea appear to develop close to but not along the sea-ice edge. As there are unfortunately no published cross-sections showing the potential vorticity distribution prior to the development of a Norwegian Sea polar low, it is not known to what degree these differences are attributed to differences in the low-level potential vorticity field.

Although polar lows are significant events, their infrequent occurrence has made it particularly difficult to obtain in-situ data regarding the environment in which they develop and their structure. This information is crucial if one wants to make any definitive statements regarding the dynamical mechanisms responsible for their development. It has traditionally been difficult to collect this sort of information because of their relatively short life cycle and occurrence over a large geographical area. For the Labrador Sea polar lows, there appears to be some well defined and relatively unambiguous precursors that may allow one to overcome these difficulties by allowing one enough lead time to deploy aircraft and ships to the area in which the development will occur. In particular, this study and previous ones (Parker and Hudson, 1991; Rasmussen and Purdom, 1992) all suggest that the formation of a linear cloud band precedes mesoscale cyclogenesis. In this study we have suggested that the polar low developed as a result of an interaction between an upper-level potential vorticity anomaly and this surface feature. A particularly interesting outcome of this study is the identification of several TOVS derived signatures of the upper-level anomaly that could again provide one with real-time information as to its existence. The identification of these features may allow for the possibility of designing an experiment to obtain in-situ aircraft and ship data regarding the environment in which the polar lows develop.

In closing, we will present a brief discussion on the potential role that polar lows may play in the formation of abyssal water in the Labrador Sea. As described by Gascard and Clarke (1983), the formation of Labrador Sea Deep Water (LSDW) occurs in stages. Proto-LSDW forms gradually over the winter as a result of the cooling associated with the continual flow of cold and dry air off the Canadian land mass. Downwelling events occurring on time scales of $12-48 \mathrm{~h}$ then turn the proto-LSDW into LSDW. This work corroborates an earlier study by Lazier (1973) that suggested that LSDW formed during sporadic oceanic convective events of short duration. These stages are in agreement with the theory of deep water formation as proposed by Killworth (1983). From a meteorological perspective, the key ingredients of Killworth's theory are a preconditioning phase during which the cooling results in an oceanic mixed layer of reduced static stability and a short phase during which intense atmospheric forcing cools the mixed layer sufficiently so as to produce a negatively buoyant plume that penetrates the thermocline. It is hypothesis worth investigating that the heat fluxes associated with a growing polar low may be the sudden and intense cooling in Killworth's theory that triggers the downwelling events of the type observed by Gascard and Clarke.

As the ECMWF analysis was unable to capture the development of the polar low under study in this paper, we unfortunately cannot use the surface heat flux diagnosed by this analysis to estimate the effect that the fluxes associated with the polar low had on the ocean. However, assuming that the only error made by the analysis was in underestimating the wind speed, one can estimate that during the most intense period of the polar low's existence, around 12 GMT on the 15th, the fluxes of sensible and latent heat were on the order of $1000 \mathrm{~W} / \mathrm{m}^{2}$. Assuming that fluxes of this magnitude persisted for $12 \mathrm{~h}$, then this amount of cooling would be sufficient to cool a 100 meter deep column of water by approximately $1^{\circ} \mathrm{C}$. This is the magnitude of cooling required to trigger a downwelling event (Gascard and Clarke, 1983).

This approximate calculation shows that it is indeed possible that polar lows may initiate downwelling events. They are, of course, not the only such triggers. Any system that produces strong winds, such as the synoptic-scale low on the 13th, in the Labrador Sea could also generate these events. From the work presented in this paper, events of sufficient magnitude to produce such strong winds, say in excess of $20 \mathrm{~m} / \mathrm{s}$, are relatively 
rare. It is interesting to note that Gascard and Clarke (1983) reported wind speeds in excess of this criterion during the period in which the downwelling occurred. They did not unfortunately report on other characteristics of the weather system that produced these winds.

In subsequent work, we will attempt to place this possible coupling between fast climate system, i.e., mesoscale cyclogenesis in the atmosphere, and the slow climate system, i.e., the thermohaline circulation in the ocean, on a more quantitative footing.

\section{Acknowledgements}

We would like to thank the NASA Climate Data System for the TOMS data, the Data Support
Section of the National Center for Atmospheric Research for the ECMWF analysis, and Remote Sensing Systems Inc. for the SSM/I data used in this paper. We would also like to thank the Atmospheric Environment Service for providing some of the HRPT data used in this paper. Funding for this research was provided by the JapanCanada Fund, the Department of Fisheries and Oceans and the Natural Sciences and Engineering Research Council of Canada. Support for the development of the satellite reception and analysis system was provided by the Environment Canada. The authors would like to acknowledge the assistance provided by Mr. M. Mackay in operating the ground station during CASP II. They would also like to thank members of the Polar Low Working Group of the European Geophysical Society for their helpful comments.

\section{REFERENCES}

Bretherton, F. P. 1966. Critical layer instability in baroclinic flows. Quart. J. Roy. Meteor. Soc. 92, 325-334.

Carmack, E. C. 1990. Large-scale physical oceanography of polar oceans. In: Polar oceanography, ed. W. O. Smith. Academic Press Inc., pp. 171-221.

Claud, C., Katsaros, K. B., Petty, G. W., Chedin, A. and Scott, N. A. 1992. A cold air outbreak over the Norwegian Sea observed with the TIROS-N Operational Vertical Sounder (TOVS) and the Special Sensor Microwave/Imager (SSM/I). Tellus 44A, 100-118.

Douglas, M. W. and Shapiro, M. A. 1989. A comparison of the structure of two polar lows observed by research aircraft. In: Polar and artic lows, ed. P. F. Twitchell, E. A. Rasmussen and K. L. Davidson. A Deepak Publishing, pp. 291-312.

Eliassen, A. and Kleinschmidt, E. 1957. Dynamic meteorology. Handbuch der Physik, ed. S. Flugge. Springer-Verlag, 48, 1-154.

Gascard, J.-C. and Clarke, R. A. 1983. The formation of Labrador Sea water. Part II. Mesoscale and smallerscale processes. J. Phys. Oceanogr. 13, 1779-1797.

Gyakum, J. R. and Barker, E. S. 1988. A case study of explosive subsynoptic-scale cyclogenesis. Mon. Wea. Rev. 116, 2225-2253.

Harley, D. G. 1960. Frontal contour analysis of a "polar low". Meteor. Mag. 89, 146-147.

Harrold, T. W. and Browning, K. A. 1969. The polar low as a baroclinic disturbance. Quart. J. Roy. Meteor. Soc. 95, 710-723.

Hoskins, B. J., McIntyre, M. E. and Robertson, A. W. 1985. On the use and significance of potential vorticity maps. Quart. J. Roy. Meteor. Soc. 111, 877-946.
Killworth, P. D. 1983. Deep convection in the world ocean. Rev. of Geophys. and Space Physics 21, 1-26.

Lazier, J. N. 1973. The renewal of Labrador Sea water. Deep-Sea Research 20, 341-353.

McPeters, R., Kreuger, A. J., Bhartia, P., Oaks, J., Ziuddin, A., Cebula, A., Schlesinger, R., Swissler, B., Taylor, T., Torres, S. and Wellemeyer, C. 1993. Nimbus-7 Total Ozone mapping Spectrometer (TOMS). Data Products User's Guide, NASA Publication \#1323.

Mote, P. W., Holton, J. R. and Wallace, J. M. 1991. Variability in total ozone associated with baroclinic waves. J. Atmos. Sci. 48, 1900-1903.

Moore, G. W. K. 1985. On the organization of Convection in the Narrow Cold-Frontal Rainband. J. Atmos. Sci. 42, 1777-1791.

Moore, G. W. K. 1990. Frontogenesis in the Presence of Surface Heating. J. Atmos. Sci. 48, 63-75.

Moore, G. W. K. and Peltier, W. R. 1989. On the development of polar low wavetrains. In: Polar and arctic lows, ed. P. F. Twitchell, E. A. Rasmussen and K. L. Davidson. A. Deepak Publishing, pp. 141-144.

Nordeng, T. E. 1990. A model-based diagnostic study of the development and maintenance mechanism of two polar lows. Tellus 42A, 92-108.

Parker, N. and Hudson, E. 1991. Polar low handbook for Canadian meteorologists, 173 pp., available from the Atmospheric Environment Service of Environment Canada.

Pedgley, D. E. 1968. A mesoscale snow system. Weather 23, 469-476.

Petty, G. W. 1990. On the response of the Special Sensor Microwave Imager to the marine environment. Implications for atmospheric parameter retrievals. $\mathrm{PhD}$ 
Dissertation, University of Washington. Available from University Microfilms, 300 North Zeeb Road, Ann Arbor, Michigan, 48106.

Rasmussen, E. A. 1985. A case study of a polar low development over the Barents Sea. Tellus 37A, 407-418.

Rasmussen, E. A. 1989. A comparative study of tropical cyclones and polar lows. In: Polar and arctic lows, ed. P. F. Twitchell, E. A. Rasmussen and K. L. Davidson. A Deepak Publishing, pp. 47-80.

Rasmussen, E. A. and Lystad, M. 1987. The Norwegian Polar Lows Project: A summary of the International Conference on Polar Lows, 20-23 May 1986. Oslo, Norway. Bull. Amer. Meteor. Soc. 68, 801-816.

Rasmussen, E. A. and Aakjær, P. D. 1989. Two polar lows affecting Denmark. Vejret, 38-48.

Rasmussen, E. A., Pedersen, T. B., Pedersen, L. T. and Turner, J. 1992. Polar lows and arctic instability lows in the Bear Island region. Tellus 44A, 133-154.

Rasmussen, E. A. and Purdom, J. F. 1992. A multisatellite investigation of a polar low development over the Labrador Sea. 6th Conference on Satellite meteorology and oceanography, 5-10 January 1992, Atlanta. American Meteorological Society.

Rasmussen, E. A., Claud, C. and Purdom, J. F. 1995. Labrador Polar Lows, submitted to GAOS.

Reed, R. J. 1986. Baroclinic instability as a mechanism for polar low development, Proceedings of the International Conference on Polar lows, Oslo, Norway, 20-23 May 1986, $364 \mathrm{pp}$. Available from the Norwegian Meteorological Institute.
Reed, R. J. 1991. Cyclogenesis from a potential vorticity perspective. Preprints from the lst International Conference on Winter storms, New Orleans, LA, 1991, 436 pp. American Meteorological Society.

Reed, R. J. and Duncan, C. N. 1987. Baroclinic instability as a mechanism for the serial development of polar lows. A case study. Tellus 39A, 376-384.

Reader, M. C. and Moore, G. W. K. 1995. Stratospheretroposphere interactions associated with a case of explosive cyclogenesis in the Labrador Sea. Tellus $\mathbf{4 7 A}$, 849-863.

Shapiro, M. A., Kreuger, A. J. and Kennedy, P. J. 1982. Nowcasting the position and intensity of jet streams using a satellite-borne total ozone mapping spectrometer. In: Nowcasting, K. A. Browning ed. Academic Press, pp. 137-145.

Shapiro, M. A., Hampel, T. and Fedor, L. S. 1987. Research aircraft observations of a polar low over the Norwegian Sea. Tellus 39A, 272-306.

Smith, W. L., Woolf, H. M., Hayden, C. M. and Schreiner, A. J. 1985. The simultaneous retrieval export package. The Technical Proceedings of the Second International TOVS Study Conference, Igls, Austria.

Thorpe, A. J. 1993. An appreciation of the meteorological research of Ernst Kleinschmidt. Meteorol. Zeitschrift 2, 3-12.

Turner, J., Lachlan-Cope, T. A. and Moore, J. C. 1992. A comparison of satellite sounding data and aircraft measurements within a mature polar low. Tellus $\mathbf{4 4 A}$, 119-132. 